\title{
YOU DON'T KNOW WHAT YOU DON'T KNOW: IMPROVEMENTS IN INVESTMENT EFFICIENCY PRIOR TO A MANDATED ACCOUNTING CHANGE
}

\author{
Derek Christensen \\ University of Wisconsin - Madison \\ dchristense6@wisc.edu \\ Dan Lynch* \\ University of Wisconsin - Madison \\ daniel.lynch@wisc.edu \\ Clay Partridge \\ University of California-Davis \\ cpartridge@ucdavis.edu
}

August 2021

\begin{abstract}
Theory suggests mandated changes in accounting standards can increase investment efficiency through two mechanisms: (1) increases in internal information quality (IIQ), and/or (2) increases in external information quality (EIQ). We leverage the transition period of the new lease accounting standard, where EIQ is unlikely to change, to isolate the effect of increases in IIQ on investment efficiency. Using a difference-in-differences design, we find that firms affected by the new lease standard experience improvements in investment efficiency in the year immediately preceding the standard's implementation. Cross-sectional tests suggest the investment efficiency gains are driven by IIQ reducing internal moral hazard risk. We contribute to the investment efficiency literature by isolating the effect of increases in IIQ on investment behavior and identifying a specific channel through which IIQ affects investment efficiency. Further, we document that preparing to comply with an accounting standard change improves managerial decision-making, which may be of use to the FASB as part of their post-implementation review of the lease accounting standard.
\end{abstract}

Keywords: investment efficiency, internal information quality, financial reporting, leases JEL codes: M41, G31, D83

* Corresponding author.

We appreciate helpful comments from Shannon Anderson, Zhiyan Cao (discussant), Elia Ferracuti (discussant), Julia Ariel-Rohr, Mallory Bennett, Katie Boylen, Amanda Carlson, Zach King, Mayer Liang, Tom Linsmeier, Ben Osswald, Jessica Nylen, Holly Skaife, Wayne Thomas, Dan Wangerin, Terry Warfield, Paul Wong, Chelle Yetman, participants at the AAA SPARK Meeting of the Regions, AAA Annual Meeting, and workshop participants at the University of California-Davis and University of Wisconsin-Madison. 


\section{Introduction}

This study examines whether and how increases in internal information quality in preparation for a mandated change in external financial reporting lead to improvements in investment efficiency. Changes in accounting standards can improve investment efficiency by (1) increasing internal information quality (IIQ) and/or (2) increasing external information quality (EIQ) (Ferracuti and Stubben 2019; Roychowdhury Shroff, and Verdi 2019). Increases in IIQ can reduce information uncertainty, internal moral hazard risk, and/or internal adverse selection risk which prevent efficient investment. Increases in EIQ can reduce external moral hazard risk and external adverse selection risk, other barriers to efficient investment. We use the positive shock to IIQ during the transition period of the new lease standard to isolate the effects of changes in IIQ on investment efficiency and investigate how increases in IIQ affect investment efficiency.

The new lease standard (ASC 842) provides a strong setting to achieve our research objective for two reasons. First, the standard provides a plausibly exogenous shock to IIQ that is particularly relevant to managers making investment decisions. Gallemore and Labro (2015) define IIQ as the quantity, accessibility, usefulness, reliability and accuracy of the information generated within an organization. ASC 842 requires firms to capitalize and report a corresponding asset and liability for all material lease transactions. This is a significant change from the previous standard requiring firms to expense operating lease payments without recording an asset or liability. To comply with the new standard, firms gathered detailed information for each lease such as the time horizon, incremental borrowing rates in regions where leases are held, the existence of renewal options, etc. For many firms, this data was dispersed throughout various cost and profit centers in the organization (Betesh 2021). Further, the standard required firms to obtain and review the contractual agreements for all lease transactions to determine their materiality threshold for 
reporting leases on the balance sheet (Tysiac 2018; Austin et al. 2020). To meet these requirements firms made substantial investments in internal technology systems and consulting services to gather, aggregate, and analyze this information (Mak 2020; Betesh 2021). These activities increased the quantity and accessibility of internal lease information, two key components of IIQ. We expect these increases in IIQ to improve firms' investment decisions.

Second, the timing of the standard's release and adoption provides a long enough transition window to observe effects unlikely to be influenced by increases in EIQ. The FASB issued the new lease standard in February 2016, effective for fiscal years ending after December 15, 2019. This implementation timeline creates a three-year transition period where firms' financial statements do not comply with ASC 842, but firms are aware and able to prepare for the forthcoming change. Using the final year of the transition period, we examine changes in investment efficiency for firms affected by the new standard relative to a group of unaffected firms before changes in financial reporting are realized. In doing so, we rely on a plausibly exogenous shock to IIQ, as opposed to measuring IIQ indirectly via external reporting which induces a positive correlation between IIQ and EIQ. This approach offers an improvement on prior literature that struggles to disentangle changes in IIQ from changes in EIQ when investigating the effects of external financial reporting requirements on investment efficiency (Bushman and Smith 2001; Ferracuti and Stubben 2019).

To implement our main analysis, we use a difference-in-differences design over the period 2015 to 2020. In our design, the treatment group consists of firm-years reporting non-zero minimum lease payments (i.e., the group of firms subject to ASC 842) and the control group consists of firm-years reporting zero minimum lease payments (i.e., non-lease firms). Following Biddle et al. (2009), we define investment efficiency as the absolute value of either the difference 
between actual investment and an industry-year median or actual investment and predicted investment based on growth opportunities. To support our difference-in-differences design, we document parallel trends in investment efficiency for lease (treatment) and non-lease (control) firms before the treatment period (Roberts and Whited 2013).

The results from our main analysis demonstrate lease firms improve investment efficiency in the final year of the transition period by between 0.531 percent and 1.051 percent of assets relative to non-lease firms. At the median value of assets in our sample, this corresponds to a $\$ 19$ million and \$38 million shift, respectively. These improvements are concentrated in the most lease intensive firms, consistent with ASC 842 preparation driving the effect and comments from practice indicating lease intensive firms gather the most information to comply with the standard (Tysiac 2019; Mak 2020; Betesh 2021). Within a sample of only lease firms, we corroborate these findings, alleviating concerns that differences between lease and non-lease firms explain our results. Further, to demonstrate our empirical design appropriately isolates IIQ, we reperform our analysis using four common measures of EIQ as the dependent variable. We do not find the improvements in investment efficiency for lease firms align with simultaneous improvements in EIQ.

To investigate whether the increases in IIQ related to ASC 842 preparation improve investment efficiency by reducing information uncertainty, internal moral hazard risk, and/or internal adverse selection risk, we perform three cross-sectional tests. First, we split our sample into firms with multiple operating segments and firms with a single operating segment. Unlike information uncertainty, internal moral hazard risk and internal adverse selection risk arise from information asymmetry between divisional and central managers. Therefore, a necessary condition for internal information asymmetry is the separation of operational decision making and central- 
management - the defining characteristic of operationally disperse firms (Giroud 2013; Chen et al. 2018). Using the same difference-in-differences design as our main analysis, we find the improvements in investment-efficiency are concentrated in the sample of operationally dispersed firms consistent with the internal moral hazard risk and/or internal adverse selection risk channels.

Second, we examine whether the improvements in investment efficiency are greater for firms with divisional managers that have an information advantage over central managers (Chen et al. 2018). While operational dispersion is necessary for internal moral hazard risk and internal adverse selection risk, it must be accompanied by an information advantage of divisional managers over central managers. The informational advantage allows divisional managers to conceal their sub optimal behavior in the case of internal moral hazard risk. For internal adverse selection risk, the information advantage dissuades central managers from allocating capital to divisional managers. Within a sample of only lease firms, we find the improvements in investment efficiency are greater when divisional managers have an information advantage over central managers. This corroborates our conclusions from the operational dispersion analysis that increases in IIQ related to ASC 842 preparation reduce internal moral hazard risk and/or internal adverse selection risk.

Third, we split our sample into chronic over-investors and chronic-under investors. Information uncertainty and internal adverse selection risk both lead to under-investment. Managers facing information uncertainty can delay investment to the future in hopes of resolving the current uncertainty. Internal adverse selection risk discourages central managers from allocating funds to divisions leading to a lack of internal financing necessary to invest efficiently. Internal moral hazard risk however, can spur over-investment and/or under-investment depending on divisional managers' incentives (e.g., empire building, effort-aversion, risk-aversion, etc.). Using the same difference-in-differences design as our main analysis, we find the improvements 
in investment efficiency accrue primarily to over-investors, consistent with the internal moral hazard risk channel. Considering the results of all three cross-sectional tests jointly, we conclude the improvements in IIQ driven by ASC 842 preparation primarily improve investment efficiency by reducing internal moral hazard risk.

We conduct multiple robustness and falsification tests. First, we employ entropy balancing and the synthetic control method to minimize observable differences between lease and non-lease firms. In both instances the conclusions we draw from our main analysis is unchanged. Second, we demonstrate our results are robust to adjusting the treatment and control period for the limited number of early adopters of ASC 842. Third, we rule out the alternative explanation that our results are driven by over-investors reducing debt-financed purchases to offset leverage increases due to operating lease capitalization under ASC 842.

Our study makes three important contributions to the academic literature and practice. First, we isolate the effects of increases in IIQ due to changes in external financial reporting requirements on the investment decisions of firms. Prior studies find investment efficiency is positively related to financial reporting quality and increases after changes in external financial reporting (Biddle et al. 2009; Cheng et al. 2013; Shroff 2017; Dou et al. 2019). However, the settings used in these studies cannot disentangle the effects of IIQ from EIQ (Bushman and Smith 2001; Ferracuti and Stubben 2019). Using the long transition period of the new lease standard, we find evidence that improvements in IIQ from a mandated change in financial reporting significantly improves investment efficiency absent contemporaneous changes in EIQ. Second, we identify a specific channel whereby IIQ affects investment efficiency. Our cross-sectional analyses suggest the increases in IIQ related to ASC 842 reduce internal moral hazard risk resulting in a decrease in over-investment. In doing so, we demonstrate one avenue in which reporting standards 
affect firm-level outcomes, a relatively understudied area in accounting research (Leuz and Wysocki 2016). Third, we inform the FASB's post implementation review of the new lease standard (FASB 2021). Our results demonstrate that certain firms experience an improvement in investment efficiency as a result of ASC 842 preparation. This unintended consequence was not considered in the FASB's pre-standard deliberation and presents new information to the standard setter (FASB 2016).

\section{Relevant Literature and Hypothesis}

\subsection{Neoclassical Perspective of Investment Efficiency}

Neoclassical investment theory states the efficient level of investment is that which maximizes the value of the firm (Modigliani and Miller 1958; Jorgensen 1963; Tobin 1969). Theoretically, the efficient level of investment is determined by the ratio of the marginal value of investment to its cost - a firm investing efficiently will undertake all investments in which the marginal value of investment is greater than its cost because doing so increases the value of the firm (Hayashi 1982). However, there is considerable variation in corporate investment that is unexplained by this ratio (Hayashi 1982; Peters and Taylor 2017). The literature identifies two primary frictions ignored by neoclassical theory that explain why firms deviate from the optimal level of investment in practice: (1) uncertainty and (2) information asymmetry (Roychowdhury et al. 2019; Ferracuti and Stubben 2019). Figure 1 illustrates the connection between these two frictions and investment efficiency.

\subsection{Uncertainty and Investment Efficiency}

Uncertainty is characterized by variation in potential outcomes of an investment decision - the greater the variation, the greater the uncertainty (Ferracuti and Stubben 2019). As uncertainty increases, mangers are less able to predict the future profitability associated with a particular investment. If the uncertain investment is irreversible, the value of delaying investment to a future 
period is positive because it allows managers to learn more about the distribution of potential outcomes before committing capital to the project (Arrow and Fisher 1974; Dixit and Pindyck 1994). ${ }^{1}$ The positive value associated with delaying investment under uncertainty causes a divergence from the optimal level of investment in a neoclassical framework because managers must weigh the marginal value of investment against not only the cost of investment but also the opportunity cost of delaying investment. Rational managers will only commit to an uncertain investment project in the current period if the expected marginal value of an investment exceeds the cost of investment plus the option value of delaying investment to the future (Arrow and Fisher 1974). Consequently, managers facing uncertainty under-invest relative to the neoclassical optimal level (see link 3 in Figure 1; Arif, Marshall, and Yohn 2016; Baek, Kwon, Lynch 2021).

\subsection{Information Asymmetry and Investment Efficiency}

There are two types of information asymmetry: (1) external information asymmetry and (2) internal information asymmetry. External information asymmetry is characterized by a separation of the ownership and control of a firm that leads to an imbalance of information between managers and capital providers (Jensen and Meckling 1976; Myers and Majluf 1984). In contrast, internal information asymmetry is characterized by a separation of decision control among managers within the firm that leads to an imbalance of information between central managers that allocate funds within the organization and divisional managers responsible for executing investment projects (Antle and Eppen 1985; Stein 2003). In both cases, the imbalance of information creates moral hazard risk and adverse selection risk that lead to inefficient investment.

\footnotetext{
${ }^{1}$ As is often the case in practice, investment decisions are reversible at a cost. The same theory applies in this case; however, the value of delaying investment is a function of the cost of reversing because delaying affords managers the potential to gain more accurate knowledge about the distribution of potential outcomes which reduces the likelihood of incurring the costs required to reverse the investment in the future.
} 
However, the nature of these risks differ depending on whether the information asymmetry is external or internal.

\subsubsection{Moral Hazard Risk}

Moral hazard risk due to external information asymmetry (external moral hazard risk) occurs when managers incentives are contrary to those of capital providers and the imbalance of information allows managers to conceal behavior that reduces the value of capital providers' claims. This behavior can manifest as over- or under-investment relative the neoclassical optimal level depending on the nature of managers incentives (see link 4 in Figure 1). Over-investment arises from empire building incentives (Ferracuti and Stubben 2019; Roychowdhury et al. 2019). Empire building occurs when managers invest in projects that have marginal values below their cost for the sole purpose of growing the assets of the firm (Jensen 1986). Intuitively, this decreases the value of the firm but may provide additional explicit or implicit compensation to managers via bonuses, changes in relative performance evaluation peer groups, perquisite consumption, etc. Under-investment arises from the disutility of effort or risk aversion (Ferracuti and Stubben 2019; Roychowdhury et al. 2019). Managers seeking a "quiet-life" forgo investment projects with a marginal value greater than their cost to avoid exerting effort (Bertrand and Mullainathan 2003). Risk averse managers may similarly forgo the same investment projects to avoid incurring additional risk (Amihud and Lev 1981).

Moral hazard risk due to internal information asymmetry (internal moral hazard risk) occurs when divisional managers incentives differ from those of the central manager charged with allocating funds within the organization and the imbalance of information allows divisional managers to conceal behavior contrary to objective of the central manager (Roychowdhury et al. 2019). This behavior can manifest as over- or under-investment relative to the neoclassical 
optimum for the same reasons that behavior from external moral hazard risk leads to over- or under-investment (see link 1 in Figure 1). However, in the case of internal moral hazard risk, empire building incentives, disutility of effort, and risk aversion all arise at the level of the divisional manager, and an information advantage over a central manager with differing incentives allows the inefficient investment to continue.

\subsubsection{Adverse Selection Risk}

Adverse selection risk due to external information asymmetry (external adverse selection risk) occurs when firm managers are able to conceal information about the quality of the firm's future prospects that is relevant to capital providers making funding decisions (Ferracuti and Stubben 2019; Roychowdhury et al. 2019). Aware of this risk, capital providers require a higher rate of return to finance the firm which increases the cost of financing investment. As a result, managers must weigh the marginal value of investment against not only the cost of the investment, but also the increase in the cost of financing due to information asymmetry (Myers and Majluf 1984). Rational managers will only invest when the marginal value of investment exceeds its cost plus the financing cost premium which leads to under-investment relative to the neoclassical optimal level (see link 5 in Figure 1).

Adverse selection risk due to internal information asymmetry (internal adverse selection risk) occurs when divisional managers are able to conceal information about the quality of the divisions' prospects that is relevant to the central manager allocating funds within the organization (Antle and Eppen 1985; Stein 2003). Aware of their informational disadvantage, the central manager withholds or diverts funds from divisional managers leading to under-investment by these divisions relative to the neoclassical optimal level (see link 2 in Figure 1).

\subsection{Effects of EIQ and IIQ on Investment Efficiency}


Two primary characteristics promote efficient investment by alleviating uncertainty and/or information asymmetries: (1) external information quality (EIQ), and (2) internal information quality (IIQ) (Ferracuti and Stubben 2019; Roychowdhury et al. 2019). As EIQ increases, external parties have a higher quantity and/or quality of information available that can lead to a reduction in external information asymmetry between managers and capital providers. ${ }^{2}$ This reduction allows capital providers to better monitor the behavior of management reducing over- and underinvestment caused by external moral hazard risk (Jensen and Meckling 1976). Similarly, capital providers are better able to judge the future prospects of the firm leading to a reduction in external adverse selection risk. This enables firms to obtain financing at a lower cost leading to a reduction in under-investment (Myers and Majluf 1984).

Various studies provide empirical support for the relationship between EIQ and investment efficiency. Biddle et al. (2009) show that higher accrual quality and $10-\mathrm{K}$ readability are contemporaneously associated with lower levels of over- and under-investment. Lara et al. (2016) find that timely loss recognition reduces the debt-equity conflict enabling under-investors to access external capital more easily leading to an improvement in investment efficiency. Cheng et al. (2013) document that changes in financial reporting quality, as evidenced by remediation of internal control weaknesses, decrease over- and under-investment. Dou et al. (2019) finds the accounting requirement to expense stock options reduces adverse selection risk allowing underinvesting firms to access the external capital necessary to finance increases in investment.

Unlike EIQ, IIQ increases the quantity and/or quality of information available to internal parties (Gallemore and Labro 2015). These improvements can serve to reduce internal information

\footnotetext{
${ }^{2}$ External financial reporting requirements can also improve investment efficiency by allowing firms to learn from peer firm financial statement disclosures (Badertscher, Shroff, White 2013; Bonsall IV, Bozanic, Fischer 2013). However, our identification strategy preempts this explanation by examining the effects of IIQ before peer firms' external financial reporting changes.
} 
asymmetry between managers within the firm by promoting better information flow between operational decision makers at the divisional level and central managers. As a result, central managers are better able to monitor the behavior of divisional managers and curb over- and underinvestment driven by internal moral hazard risk. Similarly, IIQ allows central managers to determine relevant characteristics of each division leading to a reduction in under-investment driven by internal adverse selection risk (Roychowdhury et al. 2019). Informational improvements driven by increases in IIQ can also reduce information uncertainty arising from factors that increase information processing costs within the firm. Higher IIQ makes information more easily accessible allowing managers to process information more efficiently leading to a refined assessment of the potential outcomes of an investment decision (Sims 2003; Gallemore and Labro 2015; Ferracuti and Stubben 2019). ${ }^{3}$ As a consequence, the option value of delaying investment decreases leading a reduction in under-investment.

The literature examining the relationship between IIQ and investment efficiency is sparse because disentangling the effects of IIQ from EIQ is difficult. First, at the theoretical level, EIQ and IIQ are connected (link 6 in Figure 1) because the properties of the managerial and financial accounting systems are related (Hemmer and Labro 2008). Therefore, it is difficult to identify settings in which changes in IIQ are divorced from contemporaneous changes in external financial reporting. For example, Shroff (2017) examines investment efficiency before and after the adoption of various accounting standards that are most likely to change managers internal

\footnotetext{
${ }^{3}$ Uncertainty can arise from information uncertainty or fundamental uncertainty (Ferracuti and Stubben 2019). These two sources of uncertainty differ in that firm-level factors create information uncertainty while macroeconomic factors create fundamental uncertainty. Consequently, firms can mitigate information uncertainty by gathering information but are unable to take any direct action to resolve fundamental uncertainty. For that reason, we do not incorporate a discussion of fundamental uncertainty.
} 
information sets. While his study considers the effect of IIQ on investment efficiency, it does not parse out the confounding effect of EIQ on investment efficiency.

Second, at the empirical level, IIQ is unobservable which often requires researchers to use external information to proxy for IIQ. By doing so, researchers induce a positive correlation between IIQ and EIQ (see link 7 in Figure 1). The most common empirical proxies for IIQ in the literature are the presence of internal control weaknesses, management forecast accuracy, and earnings announcement speed. Cheng et al. (2018) uses changes in management forecast accuracy to proxy for changes in IIQ driven by a mandated change in accounting for goodwill (SFAS 142). Heitzman and Huang (2019) use all three proxies to measure variation in IIQ when investigating the relationship between firm-level profit/price signals and investment efficiency. For each of these proxies, differences among firms are associated with differences in the quality and/or quantity of information available to external parties. The presence of an internal control weakness indicates firm controls and processes are inadequate at identifying errors or fraud in financial reporting. ${ }^{4}$ More accurate managerial forecasts indicate managers are better able to convey internal information to external parties. Firms that release earnings announcements to the public sooner after fiscal year end provide more timely external disclosures.

\subsection{Disentangling IIQ from EIQ}

Unlike prior studies, we break the correlation between IIQ and EIQ by leveraging the long transition period related to ASC 842. In February 2016, the FASB issued Accounting Standards Update 2016-02 requiring compliance with ASC 842 for all fiscal years ending after December 15, 2019. We focus our analysis on the final year of the transition period between December 31,

\footnotetext{
${ }^{4}$ For this reason, many studies use internal control weaknesses as a measure of financial reporting quality (Dechow et al. 2010). This further highlights the empirical connection between ICWs and the external reporting environment.
} 
2018, and December 31,2019. We expect firms incur the costs necessary to comply with ASC 842 during this period and examine the effect of the associated increases in IIQ on investment efficiency. ${ }^{5}$ Importantly, our treatment period occurs before the release of the first set of audited financial statements that incorporate the changes from ASC 842, making it improbable that systematic changes in mandated reporting for leases create a contemporaneous improvement in EIQ. Therefore, our analysis is positioned well to appropriately isolate the effect of IIQ on investment efficiency.

A critical assumption underlying our approach is the assertion that managers gather and process new information during ASC 842 preparation that improves IIQ. Because IIQ is unobservable and we deliberately rely on a setting in which changes in IIQ are unlikely to manifest as changes in common proxies based on external reporting, we rely on theory and institutional knowledge to support this assertion. Theoretically, Hemmer and Labro (2008) demonstrate the financial and managerial reporting systems are intertwined. Thus, preparation for a change in financial reporting changes the output from the managerial reporting system. For the new lease standard, the financial reporting change creates a substantial increase in the quantity and accessibility of lease information output from the managerial reporting system leading to an increase in IIQ. Under the prior lease standard, firms only needed the payment dates and payment amount for most leases to prepare their financial statements (Tysic 2019). In contrast, under ASC 842 firms must obtain new data points for each lease such as precise time horizons, borrowing rates in regions where leases are held, the existence of renewal options, the existence of purchase

\footnotetext{
${ }^{5}$ Given the standard was issued in February 2016, it is reasonable to expect that firms began preparing to comply with ASC 842 earlier than the period we examine. We believe this is not a concern in our study for two reasons. First, many firms focused their attention on compliance with the new revenue recognition standard prior to 2019 (Tysiac 2019). Second, any early preparation for ASC 842 would bias against finding results in our setting because we would attribute early preparation to the control period, which we use as a reference point.
} 
options, and more (Deloitte 2019; Mak 2020). Comments from practitioners and other stakeholders

support this conjecture, as well. Sean Torr, Managing Director of Risk and Financial Advisory

Deloitte, said this of the new lease standard:

"There is so much new data that companies haven't had in the past. Some of the companies that we've spoken to are thinking about how you leverage that data moving forward for their economic decisions." (Tysiac 2019).

In responding to the Proposed Accounting Standards Update as a part of the FASB's comment letter process, Verizon (2013) wrote:

"The proposed model, as currently written, will require extensive effort and considerable cost to implement due to its complexity. As such, we request at minimum a two-year period from the issuance of the final standard to allow entities to review their leasing portfolio and to develop appropriate lease accounting systems and required internal controls."

Similarly, Johnson and Johnson (2013) notes:

"While simplified from the original proposal, some of the elements proposed are still overly complex and would require significant resources to comply. Johnson \& Johnson has recently implemented a system to collect and maintain lease data in anticipation for the adoption of the ASU. We noted that the investment for the initial measurement was significant."

Given the theoretical and anecdotal evidence indicating preparation for ASC 842 increased the quantity and accessibility of internal information available to management, we hypothesize the new lease standard increased IIQ for affected firms leading to an increase in investment efficiency:

\section{Hypothesis: Increases in IIQ from firms preparing to comply with the lease accounting standard, ASC 842, improves firms' investment efficiency.}

To test our hypothesis, we perform three difference-in-differences analyses. First, we compare lease firms to non-lease firms to investigate the on-average effect of ASC 842 preparation on investment efficiency for affected firms. Second, we compare the improvements in investment efficiency across deciles of lease intensity, which compares each decile of lease intensity to non-lease firms. Third, we compare the improvements in investment efficiency across deciles of lease intensity within a sample of only lease firms. 


\subsection{How Does IIQ Improve Investment Efficiency?}

As the discussion of Figure 1 indicates, IIQ can improve investment efficiency by reducing information uncertainty, internal moral hazard risk, and/or internal adverse selection risk (see links 1, 2 and 3 in Figure 1). In our setting, it is ex-ante unclear which channel or combination of channels improve investment efficiency. The new lease standard forced firms to review all contracts that contained a lease or lease like elements (Tysiac 2018; Austin et al. 2020). ${ }^{6}$ If this process revealed new information to managers about the potential outcomes of pending or future investment decisions, then the improvements in IIQ related to ASC 842 preparation will reduce under-investment by reducing information uncertainty. The new lease standard also compelled firms with dispersed operations to collect and organize lease information centrally in new technology systems (Mak 2020; Betesh 2021). If these activities reduce internal moral hazard risk by revealing divisional managers' suboptimal investments, we will observe a reduction of underand/or over-investment. If these activities revealed information to central managers about divisions' profitability prospects, the increase in IIQ related to ASC 842 preparation should prompt reductions in under-investment by reducing internal adverse selection risk.

To investigate whether the improvements in IIQ improve investment efficiency by reducing information uncertainty, internal adverse selection risk, and/or internal moral hazard risk, we perform three cross-sectional tests. First, we investigate whether improvements in investment efficiency differ depending on operational dispersion. Operational dispersion is a necessary condition for internal moral hazard risk and internal adverse selection risk because it promotes

\footnotetext{
${ }^{6} \mathrm{~A}$ unique element of the new lease standard is the notion of an embedded lease. This is a lease for an asset that exists within the context of a broader contractual arrangement (Deloitte 2019). A common example is a security service contract that includes surveillance cameras on the firm's premises. While the contract is positioned as a service agreement, under ASC 842 a portion of the payments constitute a lease for the surveillance cameras. As a result, this forced firms to review many contracts that were not previously considered to contain a lease in search of embedded leases (Austin et al. 2019).
} 
decentralized decision making (Giroud 2013; Chen et al. 2018). Therefore, observing improvements in investment efficiency for operationally dispersed firms and a lack of improvement for operationally concentrated firms is consistent with reductions in internal moral hazard risk and/or internal adverse selection risk; observing the opposite is consistent with reductions in information uncertainty.

Second, we use the Chen et al. (2018) measure of internal information asymmetry to determine whether the improvements in investment efficiency accrue primarily to firms with divisional managers that have an information advantage over central managers. Similar to our operational dispersion test, finding investment efficiency improvements are greater for these firms is consistent with a reduction in internal moral hazard risk and/or internal adverse selection risk. However, this test complements our operational analysis in two ways. First, our measure of internal information asymmetry is unlikely to be correlated with information uncertainty given it requires divisional managers to have a high degree of firm specific knowledge to earn returns superior to central managers' returns. Consequently, this analysis helps to alleviate any concern that our measure of operational dispersion is correlated with information uncertainty. Second, operational dispersion must be accompanied by an information advantage of divisional managers over central managers to create internal moral hazard risk or internal adverse selection risk. Therefore, we can corroborate our conclusions form the operational dispersion analysis by using an alternative approach to proxy for the internal moral hazard risk or internal adverse selection risk channels.

Third, we examine whether the improvements in investment efficiency differ between over-investing firms and under-investing firms. The operational dispersion and internal information asymmetry tests are unable to distinguish between the internal moral hazard risk and internal adverse selection risk channels. However, a reduction in internal moral hazard risk may 
be associated with a reduction in over-investment (see link 1 of Figure 1). Alternatively, a reduction in internal adverse selection risk can only be associated with a reduction in underinvestment (see link 1 of Figure 1). Therefore, observing investment efficiency improvements for over-investors indicates ASC 842 preparation led to a reduction in internal moral hazard risk. Observing improvements for under-investors however, is consistent with reductions in internal moral hazard risk and internal adverse selection risk.

\section{Tests of Hypothesis}

\subsection{On Average - Design}

Using the following model, we examine changes in investment efficiency for lease (treatment) firms relative to non-lease (control) firms during our treatment period:

$$
\begin{aligned}
\text { EfficientInvest }_{i t}= & \beta_{0}+\beta_{1} \text { Post }_{t} * \text { LeaseInd }_{i}+\beta_{2} \text { LeaseInd }_{i}+\beta_{3} \text { Post }_{t}+ \\
& \sum_{k} \delta_{k} X_{k i t}+\rho_{l} \mid \gamma_{i}+\varepsilon_{i t}
\end{aligned}
$$

In equation (1), $i$ indexes firms, $t$ indexes fiscal years, $k$ indexes control variables, and $l$ indexes industry. We use two measures of EfficientInvest ${ }_{i t}{ }^{7}$ The first measure calculates the distance a firm-year is from its industry-year median level of investment. This approach uses the industryyear median level of investment to approximate the efficient level of investment. We first calculate total investment (TotalInvest ${ }_{i t}$ ) for each observation as the sum of net capital expenditures and net acquisitions reported on the statement of cash flows, scaled by total assets for firm $i$ in period $t$. We use the statement of cash flows to measure total investment because it excludes lease investment making it unlikely our analysis is influenced by changes in leasing activities. Next, we

\footnotetext{
${ }^{7}$ Investment efficiency is difficult to precisely measure. Thus, we use two distinctly different measures decreasing the likelihood that measurement error in our first variable is correlated with measurement error in our second variable. Therefore, results that are consistent across both measures are unlikely driven by measurement error and capture changes in the underlying construct of investment efficiency (Biddle et al. 2009).
} 
calculate the median total investment (MedianTotalinvest ${ }_{l t}$ ) within each Fama French 48 industry-year pool. Then for each observation, we subtract the median total investment for its Fama French 48 industry-year pool from its total investment. Last, we multiply the absolute value of the resulting difference by negative one hundred to assist in interpretability (increases reflect an improvement in investment efficiency):

DistanceFromEfficientInvest $_{i t}=(-100) * \mid$ TotalInvest $_{i t}-$ MedianTotalInvest $_{\text {lt }} \mid$

To create the second measure, we estimate the predicted level of investment for each firmyear observation as a function of growth opportunities using the below equation:

TotalInvest $_{i t}=\beta_{0}+\beta_{1}$ SalesGrowth $_{i t-1}+\varepsilon_{i t}$

SalesGrowt $h_{i t-1}$ is the percentage change in sales for firm $i$ from year $t-2$ to year $t-1$. We estimate the coefficients in equation (3) using ordinary least squares regression in Fama French 48 industryyear pools. ${ }^{8}$ Using the estimated coefficients, we generate the predicted level of total investment, Totallnvest ${ }_{l t}$, for each observation. We then calculate the absolute value of the difference between actual total investment and predicted total investment. We multiply this measure by negative one hundred to assist in interpretability (increases reflect an improvement in investment efficiency):

EfficientTotalInvest $_{i t}=(-100) * \mid$ TotalInvest $_{i t}-$ TotalInvest $_{l t} \mid$

This measure captures the portion of total investment not explained by growth opportunities within an industry-year and follows the approach common in prior research (Biddle et al 2009; Cheng et

\footnotetext{
${ }^{8}$ We winsorize the inputs to this model at the $1^{\text {st }}$ and $99^{\text {th }}$ percentiles by fiscal year. Additionally, we require each industry-year pool to have 20 or more observations. These choices reduce the sensitivity of our estimated coefficients in equation (2) to data errors and small samples (Biddle et al. 2009).
} 
al 2013; Lara, Osma, \& Penalva 2016). By benchmarking both measures to an industry-year, our dependent variables implicitly control for any industry-year effects.

Returning to equation (1), Post $t$ is an indicator variable we use to identify the treatment period. Post $t$ is equal to one for all observations in the final year of the transition period and is zero otherwise. This aligns with the time period we expect firms to be expending effort on ASC 842 compliance. Further, this period occurs prior to the release of the first set of audited financial statements prepared in accordance with ASC 842, making it unlikely changes in EIQ confound our results. Figure 2 depicts this identification strategy. LeaseInd $i$ identifies treatment firms. LeaseInd $_{i}$ is equal to one if the firm-year observation reports non-zero minimum lease payments

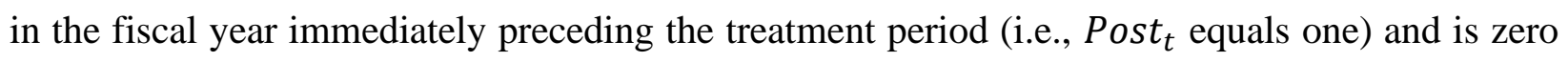
otherwise.

In equation (1) we include multiple control variables represented by $X_{k i t}$ (see Appendix 1 for variable definitions). We proxy for the magnitude and volatility of operating cash flows using CFOSales $_{i t-1}$ and $\sigma C F O_{i t-1}$, respectively. Firms that generate less cash flow from operations rely more on external parties to fund investments. Volatile operations make planning and executing multi-period investment projects more difficult. Therefore, we expect firms with volatile and small operating cash flows to invest less efficiently. We use Dividend $_{i t}$, Leverage $_{i t-1}, R O A_{i t-1}$, and $Z_{\text {Score }}$ it $-1_{1}$ to proxy for financing constraints. A firm's financial constraints are increasing in Leverage $_{i t-1}$, but decreasing in Dividend $i t, R O A_{i t-1}$, and $Z S c o r e_{i t-1}$. Prior research demonstrates that financially constrained firms face barriers to implementing positive net present value projects leading to investment inefficiencies (Kaplan and Zingales 1997; Biddle et al 2009). We include $R \& D_{i t-1}$ and Tangibility ${ }_{i t-1}$ to proxy for a firm's investment strategy. Firms with high levels of research and development expenditures may substitute physical investment with 
intangible investment. Alternatively, capital intensive firms are more likely to respond to growth opportunities with capital investment.

We control for the external information environment by including ofcruals $_{i t-1}$, AnalystFollow $_{i t}$, and InstitutionalOwn $n_{i t}$. The quality of a firm's external information environment is increasing in AnalystFollow $w_{i t}$ and InstitutionalOwn $n_{i t}$, but decreasing in

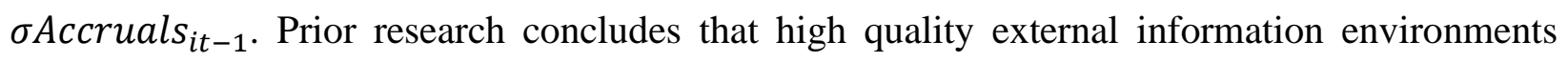
improve investment efficiency by reducing information asymmetry between management and capital providers (Biddle et al 2009; Gomariz and Ballesta 2014). We control for firm size by including $\ln A s s e t s_{i t-1}$. Larger firms possess the resources to quickly respond to growth opportunities creating greater investment efficiency. We incorporate three macroeconomic variables - Inflation $_{i t}$, DefaultSpread $_{i t}$, and RiskFree $_{i t}$. We expect that the macroeconomic environment will affect the availability and cost of financing, which are both related to firm-level investment. Last, we include SalesGrowth St-1 $_{\text {in }}$ the specification using EfficientTotalInvest $_{i t}$ as the dependent variable. Chen, et al. (2017) demonstrate using the residual from a first-stage regression as the dependent variable in a second-stage regression without incorporating the first stage predictors leads to biased inferences. In equation (1), $\rho_{l}$ and $\gamma_{i}$ represent industry and firm fixed effects, respectively.

\subsection{Lease Intensity - Design}

For our lease intensity analyses, we modify equation (1) to include a saturated decile rank of lease intensity as our treatment variable:

$$
\begin{aligned}
\text { EfficientInvest }_{i t}= & \beta_{0}+\sum_{d}\left(\beta_{d} \text { LeaseDecile }_{i d}+\gamma_{d} \text { Post }_{t} * \text { LeaseDecile }_{i d}\right)+\alpha_{1} \text { Post }_{t}+ \\
& +\sum_{k} \delta_{k} X_{k i t}+\rho_{l} \mid \gamma_{i}+\varepsilon_{i t}
\end{aligned}
$$


In equation (5), LeaseDecile $_{i d}$ is an indicator variable equal to one when the observation for firm $i$ in the year immediately preceding treatment belongs to lease intensity decile $d$, and zero otherwise. To construct the deciles, we use the total dollar value of future minimum lease payments scaled by total assets to arrange all observations in ascending order. We then assign the bottom tenth of observations to the first decile, the next tenth of observations to the second decile, and so forth. The coefficient on Post $_{t} *$ LeaseDecile $_{i d}$ captures the change in investment efficiency for firms in lease intensity decile $d$ relative to non-lease firms in our full sample analysis. In our lease firm only sample analysis, the coefficient on Post $_{t} *$ LeaseDecile $_{i d}$ captures the change in investment efficiency for firms in lease intensity decile $d$ relative to firms in the lowest decile of lease intensity.

\subsection{Sample Selection and Descriptive Statistics}

To construct our full sample, we begin with the universe of firms in Calcbench from 2015 to 2020. Calcbench captures data on future minimum leases payments for operating leases and capital leases which is essential for our lease intensity analysis. ${ }^{9}$ From the universe of firms we remove observations missing the data necessary to calculate the two dependent variables and control variables. We also remove any firms that do not have an observation for each year in the sample. ${ }^{10} \mathrm{We}$ are left with 7,200 firm-year observations (1,440 firms), constituting our main sample. Table 1 presents this sample reconciliation in detail. ${ }^{11}$

Panel A of Table 2 provides a frequency distribution of non-lease observations (LeaseInd $_{i}$ equals zero) and lease observations (LeaseInd $i$ equals one) by industry in our sample. Non-lease

\footnotetext{
${ }^{9}$ Compustat does not provide the dollar amount of minimum lease payments extending beyond five years into the future for capital leases.

${ }^{10}$ This addresses any concern that our estimates simply capture a difference in the composition of firms in the treatment period versus the control period

${ }^{11}$ All our results are robust to the exclusion of financial institutions as defined by the Fama French 48 industry classification from our main sample.
} 
observations make up 10 percent of our total sample, highlighting that non-lease firms are an economically important subset of firms. Further, each industry contains multiple lease and nonlease observations. The percentage of non-lease observations within an industry ranges from 3 percent (Wholesale Trade) to 16 percent (Finance, Insurance, and Real Estate). This alleviates the concern that lease or non-lease observations are concentrated in a small number of industries.

Panel B of Table 2 presents descriptive statistics for each variable in our sample. We winsorize each continuous variable at the $1^{\text {st }}$ and $99^{\text {th }}$ percentiles by fiscal year. The mean for EfficientTotalInvest $_{i t}$ and DistanceFromEfficient Invest It $_{i t}$ are negative 3.899 and negative 3.754 , respectively. This suggests total investment is on average 3.7 to 3.9 percent of total assets away from the efficient level of investment in our sample. Panel $\mathrm{C}$ of Table 2 presents the results from statistical tests of differences in means between lease observations and non-lease observations for each variable. For fourteen of the eighteen variables, the difference in means between lease and non-lease observations is statistically significant ( $\mathrm{p}$-value $<0.10$ ). The correlation table (Table 3) provides additional evidence that lease firms differ from non-lease firms in many observable dimensions. This highlights the need to employ a difference-in-differences design in our setting which allows treatment and control observations to differ in dimensions relevant to the dependent variable (Wooldridge 2012, p. 457).

\subsection{Assessing Parallel Trends}

The identifying assumption for a difference-in-differences analysis is parallel trends in the dependent variable between the treatment group and control group prior to the onset of treatment (Roberts \& Whited 2013). To assess the validity of this assumption, we employ two techniques. First, we graph the average value of our two investment efficiency measures for lease firms and non-lease firms through time. Figure 3 presents the resulting graphs, where panel A uses 
DistanceFromEfficientInvest $_{i t}$ as our measure of investment efficiency and panel B uses EfficientTotalinvest ${ }_{i t}$. For each graph, the red-vertical line represents the onset of treatment. In both cases, lease and non-lease firms exhibit similar trends in the control period, supporting the parallel trend assumption. Further, there is a divergence in trends in the treatment period, providing univariate support for our hypothesis.

Second, we perform a series of placebo tests by estimating equation (1) using three pseudo treatment periods that are two, three, and four fiscal years before the release of the first set of audited financial statements under ASC 842. In panel C of Figure 3, we estimate equation (1) using DistanceFromEfficientInvest $_{i t}$ as the dependent variable and in panel $\mathrm{D}$ we use EfficientTotalInvest $_{i t}$. The vertical axis in both figures is the value of our coefficient of interest, and the horizontal axis is the prescribed onset of treatment measured in years from ASC 842 (i.e., the true treatment period and three pseudo treatment periods). Each dot represents our point estimate of the coefficient on Post $_{t} *$ LeaseInd $_{i}$ and the vertical lines represent the 90 percent confidence intervals of the same coefficient. Each pseudo treatment period yields a point estimate near zero, and the 90 percent confidence interval firmly encompasses zero. This provides strong support for the parallel trend assumption. Further, in the true treatment period the point estimates and lower bounds of the 90 percent confidence intervals are above zero providing multivariate support for our hypothesis.

\subsection{Results - Test of Hypothesis}

Table 4 presents the results from estimating equation (1). In columns 1 and 2, we use DistanceFromEfficientInvest ${ }_{i t}$ as our measure of investment efficiency, and in columns 3 and 4, we use EfficientTotalInvest $_{i t}$. Columns 1 and 3 include industry fixed effects, while columns 2 and 4 include firm fixed effects. In all specifications, we cluster standard errors by firm. The 
estimate of the coefficient on Post $_{t} *$ LeaseInd $_{i}$ is positive across all columns and statistically significant in two of four specifications (p-value $<0.10$ ). Our estimate in column 1 suggests lease firms move 1.051 percent of total assets closer to the median investment level in their industry. Applying the median value of total assets in our sample, this translates to a move of $\$ 38$ million. ${ }^{12}$

Table 5 presents the results from estimating equation (5). The column structure is identical to Table 4. Panel A presents our estimation using the full sample of lease and non-lease firms, while panel B presents our results within the sample of lease firms only. In Panel A, the magnitudes of the positive coefficients on Post $_{t} *$ LeaseDecile $_{i d}$ are the largest for the top three deciles and statistically significant $(\mathrm{p}$-value $<0.10)$ for the top decile across all four specifications. In Panel B, the magnitudes of the positive coefficients on Post $_{t} *$ LeaseDecile $_{i d}$ are the largest for the top three deciles and statistically significant $(\mathrm{p}$-value $<0.10)$ for the top two deciles across all four specifications. Overall, the results of Table 4 and 5 support our hypothesis that increases in IIQ from preparing to comply with ASC 842 lead to improvements in investment efficiency.

\subsection{EIQ Falsification}

Underlying the tests of our hypothesis is the assumption that lease firms' external information environment does not improve during the ASC 842 transition period relative to nonlease firms. To formally test this assumption, we re-estimate equation (1) after replacing our investment efficiency dependent variables with four variables that proxy for EIQ (Balakrishnan et al. 2019): (1) bid ask spread - BidAsk $k_{i t}$, (2) analyst forecast dispersion - AnalystDisp ${ }_{i t},(3)$

\footnotetext{
${ }^{12}$ The median value of total assets for lease firms in the full sample is $\$ 3.66$ billion. $\$ 3.66$ billion times $1.051 \%$ is $\$ 38$ million.
} 
analyst forecast error - AnalystError ${ }_{i t}$, and (4) idiosyncratic return volatility - IdioRetVol ${ }_{i t}$, (see Appendix 1 for variable definitions). ${ }^{13}$

Table 6 presents the results from our EIQ analyses. We find no evidence that EIQ improves for lease firms relative to non-lease firms during our treatment period. ${ }^{14}$ Furthermore, to ensure non-lease firms provide an appropriate counterfactual for lease firms in these analyses, we graph the trends in each EIQ proxy. We also perform placebo tests using three alternative pseudo treatment periods that are two, three, and four fiscal years before the release of the first set of audited financial statements under ASC 842. Figure 4 presents the graphs for the four EIQ proxies and suggests non-lease firms are an appropriate counterfactual.

\section{Tests of How IIQ Improves Investment Efficiency}

\subsection{Operating Dispersion - Design}

To examine whether the improvements in investment efficiency for lease firms are driven by operationally dispersed or operationally concentrated firms, we estimate equation (1) in a sample of multi-segment firms and a sample of single segment firms. In doing so, we measure operational dispersion using the presence of multiple operating segments.

\subsection{Internal Information Asymmetry - Design}

Using the following model, we examine whether the improvements in investment efficiency for lease firms are greater for firms with divisional managers that have an information advantage over central managers:

\footnotetext{
${ }^{13}$ For this analysis we also adjust the vector of control variables by removing variables unrelated to EIQ and including a lagged loss indicator, the beginning of year market-to-book ratio, and the natural log of the number of years a firm has been publicly traded.

${ }^{14}$ Results are robust to the inclusion of firm fixed effects.
} 
EfficientInvest $_{i t}=\beta_{0}+\beta_{1}$ Post $_{t} *$ DivAdvantage $_{i}+\beta_{2}$ DivAdvantage $_{i}+\beta_{3}$ Post $_{t}+$

$$
\sum_{k} \delta_{k} X_{k i t}+\rho_{l} \mid \gamma_{i}+\varepsilon_{i t}
$$

EfficientInvest ${ }_{i t}$, the vector of control variables $X_{k i t}$, Post $_{t}$, and fixed effects $\rho_{l} \mid \gamma_{i}$ are identical to those in equation (1). However, DivAdvantage $e_{i}$ is an indicator variable equal to one for firms with divisional managers that earn higher abnormal profits on insider trades than corporate managers, and zero otherwise. We obtain the data to create this measure from the website of one of the authors of Chen et al. (2018) which creates and validates this measure. ${ }^{15}$ Due to data restrictions, we fix the value of DivAdvantage $e_{i}$ for each firm based on the fiscal year of 2016. Further, we estimate equation (6) within a sample of lease firms because there are too few nonlease firms with the data necessary to create DivAdvantage . $_{\text {. }}$

\subsection{Over- and Under-Investors - Design}

To perform the over- and under-analysis, we estimate equation (1) within a sample of chronic over-investors and a sample of chronic under-investors. We use both dependent variables (DistanceFromEfficientInvest ${ }_{i t}$ and EfficientTotalInvest ${ }_{i t}$ ) to construct each sample, creating two permutations of the under-investing sample and two permutations of the overinvesting sample -4 samples total. To be included in the first (second) sample, we require a firm to have TotalInvest $t_{i t}$ fall below (exceed) MedianTotalInvest $t_{l t}$ for the entire control period. To be included in the third (fourth) sample, we require a firm to have TotalInvest ${ }_{i t}$ fall below (exceed) Totallnvest ${ }_{l t}$ for the entire control period. By requiring a firm to exhibit under- or overinvesting behavior for all years of the control period, we isolate firms that chronically deviate from the efficient level of investment in a particular direction.

\footnotetext{
${ }^{15} \mathrm{We}$ thank the authors for making their data available. See http://www.xiuminmartinwustl.com/research.html for a link to the data the authors use in Chen et al. (2018) and we use for this analysis.
} 


\subsection{Results - Channel Analysis}

Panel A and B of Table 7 presents the results from our operational dispersion analysis within the multi-segment firm sample and single-segment sample, respectively (the column structure is identical to Table 4). For multi-segment firms, the estimates of the coefficient on Post $_{t} *$ LeaseInd $_{i}$ are positive across all four specifications and statistically significant in two of four specifications ( $\mathrm{p}$-value $<0.10)$. In contrast, the coefficient estimates are negative and not statistically significant across all four specifications for single-segment firms suggesting operationally dispersed firms are the primary beneficiary of ASC 842 preparation.

Table 8 presents the results from our internal information asymmetry analysis (the column structure is identical to Table 4). The estimates of the coefficients on Post $_{t} *$ DivAdvantage $_{i}$ is positive across all four specifications and statistically significant (p-value $<0.10)$ in the two specifications that employ firm fixed effects suggesting the improvements in investment efficiency are concentrated among lease firms with divisional managers that have an information advantage over central managers.

Panel A and B of Table 9 present our results from estimating equation (1) in each of the under- and over-investing samples, respectively (the column structure is identical to Table 4). Within the two under-investing samples, the coefficient on Post $t$ * LeaseInd ${ }_{i t}$ is not statistically significant at conventional levels in any of the four specifications. However, in the two overinvesting samples the coefficient on Post $_{t} *$ LeaseInd $_{i t}$ is positive and statistically significant in all four specifications ( -value $<0.10)$ suggesting the improvements in investment efficiency largely accrue to over-investors.

Taken together, the results of these cross-sectional tests suggest increases in IIQ related to ASC 842 preparation improve investment efficiency by reducing internal moral hazard risk. The 
lack of improvements in investment efficiency for single segment lease firms or lease firms with an information balance internally is inconsistent with reductions of information uncertainty driving our primary findings. Unlike internal moral hazard risk and internal adverse selection risk, information uncertainty does not depend on operational dispersion or internal information asymmetry to create inefficient investment. Our finding that the investment efficiency benefits of ASC 842 preparation largely accrue to over-investors corroborates this conclusion because information uncertainty does not lead to over-investment. Further, the over- and under-investor analysis suggests the IIQ gains from ASC 842 preparation does not reduce internal adverse selection risk. Like information uncertainty, internal adverse selection risk does not spur overinvestment. However, internal moral hazard risk can lead to over-investment by creating empire building incentives. Therefore, an improvement in investment efficiency for only over-investors is consistent with a reduction in internal moral hazard risk.

\section{Robustness and Falsification Analyses}

\subsection{Entropy-balancing}

Lease and non-lease firms in our sample exhibit statistically significant differences across many control variables included in our analyses. To alleviate concerns that our results are driven by functional form misspecification, we re-estimate equation (1) and (5) after entropy balancing on the first for each control variable (Shipman et al. 2017). Panel A of Table 10 presents tests of differences in means between lease and non-lease firms for our control variables after entropy balancing. The differences in means between all control variables are not statistically significant and equal to zero. Panel B and C of Table 10 presents our estimation of equation (1) and (5) in the entropy balanced sample, respectively. Panel C of Table 10 presents our estimation of equation (5) 
in the entropy balanced sample. Our estimates of the coefficient on Post ${ }_{t} *$ LeaseInd $_{i}$ and Post $_{t} *$ LeaseDecile $_{i d}$ are consistent with our primary results.

\subsection{Synthetic Controls}

For each difference-in-differences analysis, we rely on a parallel trends assumption. Although Figure 3 and our pseudo-event analysis supports the parallel trends assumption, the investment efficiency trends for lease and non-lease firms do not move in perfect harmony during the control period. To demonstrate our results are not an extreme manifestation of the idiosyncratic differences between lease and non-lease firms seen in the control period, we apply a synthetic control. A synthetic control approach is best suited for difference-in-differences analysis related to changes in public policy when a suitable sample of control observations do not exist (Abadie 2020). This method relies on an optimization technique to generate weights for control observations that ensure the weighted average of control observations (i.e., the synthetic control observation) behave identically to treatment observations in a specified dimension (Abadie 2020). The relevant dimension in our setting is investment efficiency. This technique allows us to estimate the treatment effect as the average value of the relevant variable for the treated observations, less the value of the relevant variable for the synthetic control observation in the treatment period. Panel A and B of Figure 5 provides graphical depictions of our synthetic control estimates using EfficientTotalInvest $_{i t}$ and DistanceFromEfficientInvest ${ }_{i t}$ as the relevant dimension for comparison, respectively. In both graphs, investment efficiency for the synthetic control perfectly mirrors the average investment efficiency of our treated observations in the control period, by design. Additionally, we observe an increase in average investment efficiency for lease firms relative to the synthetic control in the treatment period, supporting our primary results.

\subsection{Early Adopters}


In our sample, there are 39 of 1,440 firms that adopted the lease standard early (roughly two percent). Given early adopters release audited financial statements in accordance with ASC 842 before December $15^{\text {th }}, 2019$, the external information environment changes for these firms before the end our treatment period. To ensure our results are not driven by this small group of firms, we re-estimate equation (1) and (5) after adjusting the onset of treatment for early adopters

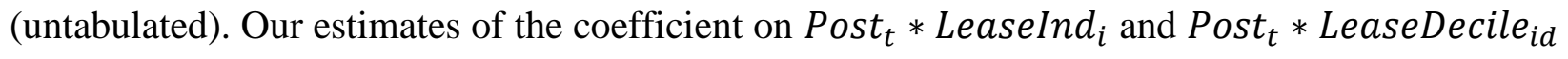
are consistent with our primary results.

\subsection{Change in Non-Lease Leverage Falsification Test}

A potential alternative explanation for our results is that firms fearing debt-covenant violations counteract the negative effect of the standard on common debt ratios by reducing debt financed investments. If this subset of firms are disproportionately over-investing firms this would lead to improvements in investment efficiency during our treatment period unrelated to ASC 842 induced changes in IIQ. To address this alternative explanation, we form quintiles of firms based on the change in leverage excluding operating lease liabilities in the year of ASC 842 adoption. Within each quintile, we estimate equation (1). If the proposed alternative explanation drives our results, we expect to find the coefficient on Post $_{t} *$ LeaseInd $_{i t}$ is strongest in the bottom quintiles - firms that reduced their non-operating lease debt the most when adopting ASC 842. Untabulated results do not support this pattern. The coefficient on Post $_{t} *$ LeaseInd $_{i t}$ is the largest in the third quintile across all specifications (i.e., both dependent variables and types of fixed effects - industry and firm) and the coefficient in the bottom two quintiles is not statistically significant in any specification ( $\mathrm{p}$-value $>0.10$ ).

\section{Conclusion}


This study leverages the transition period of ASC 842 to isolate and document the positive effect of increases in IIQ on investment efficiency. The results suggest firms most affected by the new lease standard experience the greatest efficiency gains. Further, the improvements in investment efficiency accrue primarily to firms with multiple operating segments, divisional managers that have an information advantage over central managers, and over-investing firms consistent with a reduction in internal moral hazard risk. These findings contribute to the literature by isolating the positive effects of increases in IIQ from complying with external financial reporting requirements on managerial decision-making. We document a positive unintended consequence of ASC 842 that should be of interest to practitioners and standard setters as they evaluate one of the most significant accounting standards of the past decade. Further, we add to the investment efficiency literature by showing that IIQ can reduce internal moral hazard risk.

Our study is subject to certain caveats. First, proxies for investment efficiency are imprecise measures. We employ two different measures established in prior literature to alleviate this imprecision. However, we cannot fully rule out that measurement error contributes to our results. Second, IIQ is inherently unobservable. We rely on prior theoretical work (Hemmer and Labro 2008), institutional knowledge, comments from practitioners and auditors, and the burdensome compliance requirements related to ASC 842 to identify changes in IIQ. However, if we fail to adequately identify changes in IIQ, it is difficult to interpret our results. We believe our results that show the largest increases in investment efficiency accrue to firms that must expend the most effort gathering information to comply with the new standard alleviates this concern (i.e., the most lease intensive firms). Last, our results cannot inform on the cost of ASC 842 compliance. Therefore, we make no assertion that the investment efficiency gains outweigh the costs of gathering, storing, and reporting new lease information. Despite these caveats, our study makes a 
significant and timely contribution to the literature by isolating the effects of increases in IIQ due to ASC 842 preparation on investment efficiency. 


\begin{tabular}{|c|c|}
\hline \multicolumn{2}{|r|}{$\begin{array}{l}\text { Appendix } 1 \\
\text { Variable Definitions }\end{array}$} \\
\hline Variable & Definition \\
\hline \multicolumn{2}{|l|}{ Dependent Variables } \\
\hline TotalInvest $_{i t}$ & $\begin{array}{l}\text { The sum of capital expenditures and acquisitions less divestitures and sales of } \\
\text { PP\&E, scaled by total assets for firm } i \text { in period } t \text {. }\end{array}$ \\
\hline MedianTotalInvest $_{l t}$ & $\begin{array}{l}\text { The median value of TotalInvest for industry } l \text { in year } t \text { where industry is } \\
\text { defined by the Fama French } 48 \text {. }\end{array}$ \\
\hline DistanceFromEfficientInvest $_{i t}$ & $\begin{array}{l}\text { The difference between TotalInvest for firm } i \text { in year } t \text { and the median } \\
\text { TotalInvest for firm } i^{\prime} \text { s Fama French } 48 \text { industry in year } t \text {. }\end{array}$ \\
\hline EfficientTotalInvest $_{i t}$ & $\begin{array}{l}\text { The absolute value of the actual level of investment less the predicted level of } \\
\text { total investment for firm } i \text { in year } t \text {, multiplied by negative one hundred. } \\
\text { Predicted level of investment is the fitted value for firm } i \text { in year } t \text { from a } \\
\text { model of Totallnvest regressed on SalesGrowth within Fama French } 48 \\
\text { industry-year pools. }\end{array}$ \\
\hline BidAsk $_{i t}$ & $\begin{array}{l}\text { The average of the difference between the closing asking stock price and } \\
\text { closing bidding stock price for each trading day during the fiscal year ended in } \\
\text { year } t \text { for firm } i \text {. }\end{array}$ \\
\hline AnalystDisp $_{i t}$ & $\begin{array}{l}\text { The standard deviation of analyst forecasts made in the } 3 \mathrm{rd} \text { month prior to the } \\
\text { month of firm } i^{\prime} \text { s earnings announcement for fiscal year } t \text {. }\end{array}$ \\
\hline AnalystError $_{i t}$ & $\begin{array}{l}\text { The difference between realized EPS for firm } i \text { in fiscal year } t \text { and the median } \\
\text { analyst forecasted EPS for firm } i \text {, in the } 3 \text { rd month prior to the month of firm } \\
i \text { 's earnings announcement for fiscal year } t \text {. }\end{array}$ \\
\hline IdioReturnVol $_{i t}$ & $\begin{array}{l}\text { The standard deviation of firm } i \text { 's return residuals from the market model using } \\
\text { monthly returns for the period year } t-4 \text { to year } t \text {. }\end{array}$ \\
\hline \multicolumn{2}{|l|}{ Treament Variables } \\
\hline LeaseInd $_{i}$ & $\begin{array}{l}\text { For the control period, indicator equal to one if firm } i \text { in year } t \text { has non-zero } \\
\text { minimum lease payments, and zero otherwise. For the treatment period } \\
\text { indicator equal to one if firm } i \text { in year } t-1 \text { has non-zero minimum lease } \\
\text { payments, and zero otherwise. Given the treatment period is } 1 \text { year long, this } \\
\text { ensures the value for firm } i \text { in the treatment period is the same as the value } \\
\text { immediately before the onset of treatment. }\end{array}$ \\
\hline LeaseIntensity $_{i t}$ & $\begin{array}{l}\text { The sum of total minimum lease payments for both capital and operating leases } \\
\text { scaled by total assets for firm } i \text {, and year } t \text {. }\end{array}$ \\
\hline LeaseDecile $_{\text {id }}$ & $\begin{array}{l}\text { For the control period, indicator variable equal to one when the observation } \\
\text { for firm } i \text { in year } t \text { belongs to LeaseIntensity decile } d \text {, and zero otherwise. } \\
\text { For the treatment period, indicator variable equal to one when the observation } \\
\text { for firm } i \text { in year } t \text { - } 1 \text { belongs to LeaseIntensity decile } d \text {, and zero otherwise. } \\
\text { Given the treatment period is } 1 \text { year long, this ensures in the value for firm in } \\
\text { the treatment period is the same as the value immediately before the onset of } \\
\text { treatment. }\end{array}$ \\
\hline Post $_{t}$ & $\begin{array}{l}\text { Indicator equal to one for all observations in the final year of the ASC } 842 \\
\text { transition period, and zero otherwise. }\end{array}$ \\
\hline
\end{tabular}




\begin{tabular}{|c|c|}
\hline \multicolumn{2}{|l|}{ Treament Variables } \\
\hline DivAdvantage $_{i}$ & $\begin{array}{l}\text { Indicator variable equal to one if the cumulative size adjusted trading returns } \\
\text { arising from opportunistic insider trades is greater for divisional managers } \\
\text { than central managers over the three fiscal years ending in } 2016 \text { for the firm } i \text {. } \\
\text { We obtain the data for this measure from } \\
\text { http://www.xiuminmartinwustl.com/research.html, the website of one of the } \\
\text { authors of Chen et al (2018) which creates and validates this measure. }\end{array}$ \\
\hline \multicolumn{2}{|l|}{ Control Variables } \\
\hline SalesGrowth $_{i t-1}$ & The percentage change in sales for firm $i$ from year $t-2$ to year $t-1$. \\
\hline CFOSales $_{i t-1}$ & The ratio of cash flows from operations to total revenue for firm $i$ in year $t-1$. \\
\hline$\sigma C F O_{i t-1}$ & $\begin{array}{l}\text { The standard deviation of cash flows from operations for firm } i \text { from year } t-5 \\
\text { to year } t-1 \text {. }\end{array}$ \\
\hline Dividend $_{i t}$ & Indicator equal to one if firm $i$ pays a dividend in year $t$, and zero otherwise. \\
\hline$R O A_{i t-1}$ & Pre-tax income scaled by beginning of year assets for firm $i$ in year $t-1$. \\
\hline Leverage $_{i t-1}$ & The ratio of total debt to total assets for firm $i$ at the end of year $t-1$. \\
\hline Zscore $_{i t-1}$ & The Altman Z-score measure of financial distress for firm $i$ in year $t-1$. \\
\hline$R \& D_{i t-1}$ & $\begin{array}{l}\text { Research and development expenditures scaled by total assets for firm } i \text { in } \\
\text { year } t-1 \text {. }\end{array}$ \\
\hline Tangibility $_{i t-1}$ & The ratio of PP\&E to total assets for firm $i$ at the end of year $t$. \\
\hline oAccruals $_{i t-1}$ & $\begin{array}{l}\text { The standard deviation of the discretionary accruals for firm } i \text { from year } t-5 \\
\text { to year } t-1 \text {. We use a modified Dechow \& Dichev (2002) accruals model to } \\
\text { calculate discretionary accruals for each firm-year }\end{array}$ \\
\hline $\operatorname{lnAssets}_{i t-1}$ & The natural $\log$ of total assets for firm $i$ at the beginning of the year $t$ \\
\hline AnalystFollow $_{i t}$ & $\begin{array}{l}\text { The number of analysts issuing earnings per share forecasts for firm } i \text { in the } \\
\text { month immediately preceding the firm's earnings announcement for year } t \text {. }\end{array}$ \\
\hline InstitutionalOwn $_{i t}$ & A Herfindahl index of institutional ownership for firm $i$ in year $t$. \\
\hline Inflation $_{i t}$ & $\begin{array}{l}\text { The inflation for the one-year period ending on firm } i^{\prime} \text { s fiscal year end date for } \\
\text { year } t \text {. }\end{array}$ \\
\hline DefaultSpread $_{i t}$ & $\begin{array}{l}\text { The average Aaa to Baa credit spread for the one-year period ending on firm } \\
i \text { 's fiscal year end date for year } t \text {. }\end{array}$ \\
\hline RiskFree $_{\text {it }}$ & $\begin{array}{l}\text { The average yield on one-month US treasuries for the one-year period ending } \\
\text { on firm } i \text { 's fiscal year end for year } t \text {. }\end{array}$ \\
\hline
\end{tabular}




\section{References}

Abadie, A. 2020. Using Synthetic Controls: Feasibility, Data Requirements, and Methodological Aspects. Journal of Economic Literature, forthcoming.

Amihud, Y., and Lev., B. 1981. Reisk reduction as a managerial motive for conglomerate mergers. The Bell Journal of Economics. 605-617.

Antel, R., and Eppen, G. 1983. Capital Rationing and Organizational Slack in Capital Budgeting. Management Science. 31(2), 163-174.

Arif, S., Marshall, N., and Yohn, T. 2016. Understanding the relation between accruals and volatility: A real options-based investment approach. Journal of Accounting and Economics: 62(1), 65-86.

Arrow, K.J., Fisher, A.C. 1974. Environmental Preservation, Uncertainty, and Irreversibility. In: Gopalakrishnan C. (eds) Classic Papers in Natural Resource Economics. Palgrave Macmillan, London.

Austin, S., Colbourn, J., Doolittle, P., and Renner, D. 2020. Lease accounting standard requires new auditor judgements. Journal of Accountancy. https://www.journalofaccountancy.com/issues/2020/mar/lease-accounting-requires-newauditor-judgments.html

Austin S., Colbourn, J., Gibbons, K. 2019. Hidden in plain sight: Accounting for embedded leases. Journal of Accountancy. https://www.journalofaccountancy.com/news/2019/sep/financial-reporting-embeddedleases-201921885.html.

Badertscher, B., Shroff, N., \& White, H. D. 2013. Externalities of public firm presence: Evidence from private firms' investment decisions. Journal of Financial Economics, 109 (3), 682706.

Baek, I., Kwon, S., and Lynch, D. 2021. The Effect of Common Ownership on Investment Decisions under Uncertainty. Working paper, University of Wisconsin - Madison.

Balakrishnan, K., Blouin, J., and Guay, W. 2019. Tax aggressiveness and corporate transparency. The Accounting Review. 94 (1), 45-69.

Betesh, M. 2021. Uncover an Unlikely Profit Center: Transforming Lease Compliance into Savings Opportunities. Forbes. Available at:

https://www.forbes.com/sites/forbesrealestatecouncil/2021/02/04/uncover-an-unlikelyprofit-center-transforming-lease-compliance-into-savingsopportunities/?sh=5a480300a0d8

Bertrand, M., and Mullainathan, S. 2003. Enjoying the quiet life? Corporate governance and managerial preferences. Journal of Political Economics. 111(5), 1043-1075.

Biddle, G.C., Hilary, G., and Verdi, R.S. 2009. How does financial reporting quality relate to investment efficiency? Journal of Accounting and Economics. 48, 112-131.

Bonsall IV, S. B., Bozanic, Z., and Fischer, P. E. (2013). What do management earnings forecasts convey about the macroeconomy? Journal of Accounting Research, 51 (2), 225 266.

Bushman, R.M., and Smith, A.J., 2001. Financial accounting information and corporate governance. Journal of Accounting and Economics 32 (1-3), 237-333.

Chen, C., Martin, X., Roychowdhury, S., Wang, X., and Billett, M. 2018. Clarity Begins at Home: Internal Information Asymmetry and External Communication Quality. The Accounting Review. 93 (1), 71-101. 
Chen, W., Hribar, P., and Melessa, S. 2017. Incorrect Inferences When Using Residuals as Dependent Variables. Journal of Accounting Research. 56 (3), 751-796.

Cheng, M., Dhaliwal, D., and Zhang, Y. 2013. Does investment efficiency improve after the disclosure of material weaknesses in internal control over financial reporting? Journal of Accounting and Economics. 56, 1-18.

Cheng, Q., Cho, Y.J., and Yang, H. 2018. Financial reporting changes and the internal information environment: Evidence from SFAS 142. Review of Accounting Studies, 23 (1), 347-383.

Dechow, P., Ge, W., and Schrand, C. 2010. Understanding earnings quality: A review of the proxies, their determinants and their consequences. Journal of Accounting and Economics. 50, 344 - 401.

Deloitte. 2019. A roadmap to applying the new leasing standard. Deloitte. Available at https://www2.deloitte.com/content/dam/Deloitte/us/Documents/audit/ASC/Roadmaps/usaers-a-roadmap-to-applying-the-new-leasing-standard.pdf

Dixit, A.K., and Pindyck, R.S. 1994. Investment under Uncertainty. Economics Books.

Dou, Y., Wong, M.F., and Xin, B. 2019. The effect of financial reporting quality on corporate investment efficiency: evidence from the adoption of SFAS No. 123R. Management Science. 65, 1949-2443.

Farr, L. 2018. Tips for lease accounting implementation. Journal of Accountancy. Available at: https://www.journalofaccountancy.com/news/2018/jan/fasb-lease-accountingimplementation-201818092.html

Ferracuti, E., and Stubben, S.R., 2019. The role of financial reporting in resolving uncertainty about corporate investment opportunities. Journal of Accounting and Economics 68 (3), 101248.

Financial Accounting Standards Board (FASB). 2021, March 5. Topic 842, Leases [Webinar]. Financial Accounting Foundation.

Gallemore, J., and Labro, E. 2015. The important of the internal information environment for tax avoidance. Journal of Accounting and Economics 60, 149-167.

Giroud, X. 2013. Proximity and Investment: Evidence from Plant Level Data. The Quarterly Journal of Economics. 128(2), 861-915.

Gomariz, M. F. C., and J. P. S. Ballesta. 2014. Financial reporting quality, debt maturity and investment efficiency. Journal of Banking \& Finance 40: 494-506.

Goodman, T., Neamtiu, M., Shroff, N., and White, H. 2014. Management forecast quality and capital investment decisions. The Accounting Review 89 (1), 331-365.

Hayashi, F. 1982. Tobin's Marginal q and Average q: A Neoclassical Interpretation. Econometrica. 50 (1), 213-24.

Heitzman, S. and Huang, M., 2019. Internal Information quality and the sensitivity of investment to market prices and accounting profits. Contemporary Accounting Research 36 (3), 1699-1723.

Hemmer, T., and Labro, E. 2008. On the Optimal Relation between the Properties of Managerial and Financial Reporting Systems. Journal of Accounting Research 46 (5), 1,209 - 1,240.

Jensen, M. 1983. Agency costs of free cash flow, corporate finance, and takeovers. American Economic Review. 76, 323-329.

Jensen, M., and W. Meckling. 1976. Theory of the firm: Managerial behavior, agency costs and ownership structure. Journal of Financial Economics. 3 (4), 305-360. 
Johnson and Johnson. Comment Letter in response to exposure draft: Lease (Topic 842). August 27, 2013.

Jorgenson, D. (1963). Capital Theory and Investment Behavior. The American Economic Review. 53(2): 247-259.

Kaplan, S. and L. Zingales. 1997. Do Investment-Cash Flow Sensitivities Provide Useful Measures of Financing Constraints? The Quarterly Journal of Economics 112 (1), 169215

Lara, J. M. G., Osma, B. G., and Penalva, F. 2016. Accounting conservatism and firm investment efficiency. Journal of Accounting and Economics, 61 (1), 221-238.

Leuz, C., Wysocki, P. (2016). "The Economics of Disclosure and Financial Reporting Regulation: Evidence and Suggestions for Future Research", Journal of Accounting Research, 54 (2), 525-622

Ma, M., Thomas, W. 2021. Economic Consequences of Operating Lease Recognition. Working paper, University of Oklahoma.

Mak, K. 2020. Still Procrastinating on ASC 842 Implementation? 8020 Consulting. Available at: https://8020consulting.com/asc-842-implementation/.

Myers, S., and Majluf, N. 1984. Corporate financing and investment decisions when firms have information that investors do not have. Journal of Financial Economics. 13 (2), 187-221.

Peters, R., and L. Taylor. 2017. Intangible capital and the investment-q relation. Journal of Financial Economics. 123 (2), 251-272.

Roberts, M.R., and Whited, T.M. 2013. Chapter 7 - Endogeneity in Empirical Corporate Finance. Handbook of the Economics of Finance. Volume 2 Part A 493-572.

Roychowdhury, S., Shroff, N., and Verdi, R.S., 2019. The effects of financial reporting and disclosure on corporate investment: A review. Journal of Accounting and Economics 68, 101246.

Shipman, J.E., Swanquist, Q.T., Whited, R.L., 2017. Propensity score matching in accounting research. The Accounting Review, 92 (1), 213-244.

Shroff, N. 2017. Corporate investment and changes in GAAP. Review of Accounting Studies, 22 (1), 1-63.

Sims, C.A., 2003. Implications of rational inattention. Journal of Monetary Economics 50 (3), 665-690.

Stein, J. 2003. Agency, information, and corporate investment. Handbook of Economics and Finance, 111-165.

Tobin, J. (1969). A General Equilibrium Approach to Monetary Theory. Journal of Money, Credit, and Banking. 1 (1), 15-29.

Tysiac, K. 2018. Lease accounting laggards face serious risks. Journal of Accountancy. Available at: https://www.journalofaccountancy.com/news/2017/aug/lease-accountingstandard-implementation-201717159.html

Tysiac, K. 2019. Lease accounting tips for public and private companies. Journal of Accountancy. Available at: https://www.journalofaccountancy.com/news/2019/apr/leaseaccounting-implementation-tips-201920943.html

Verizon. 2013. Comment Letter in response to exposure draft: Lease (Topic 842). September 13, 2013.

Wooldridge, J. M. 2012. Introductory econometrics: a modern approach ( $5^{\text {th }}$ Edition). Southwestern College Publishing, Nashville, T ATN, 41. 
Figure 1: Theoretical Relationship Between IIQ, EIQ, and Investment Efficiency

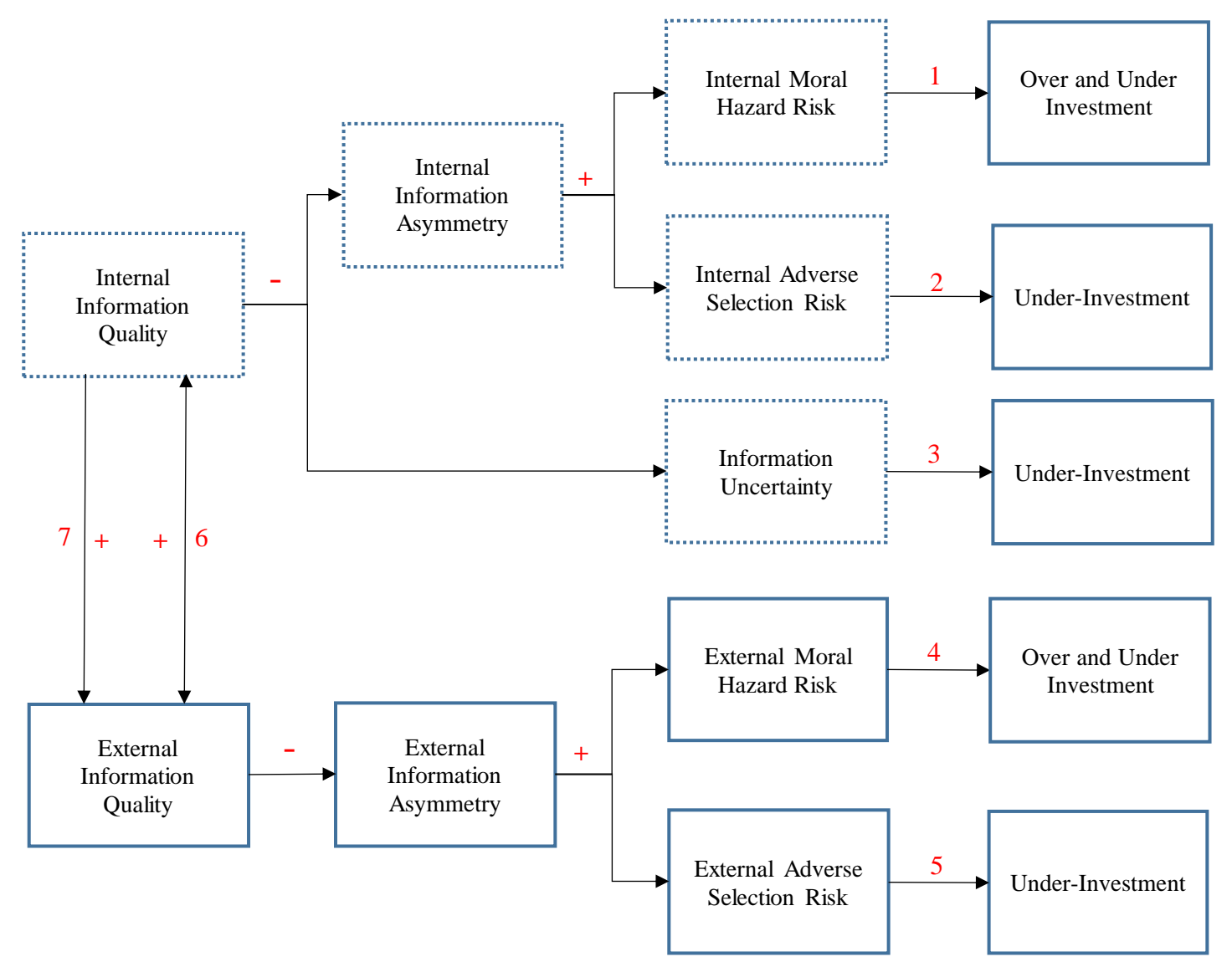

Note: This figure depicts the theoretical connectin between internal information quality, external information quality, and investment efficiency. All dashed boxes indicate the relevant construct is uonbservable to parties external to the firm. This highlights the channels through which a change in financial reporting can affect investment efficinecy via increases in internal information quality and/or external information quality. 


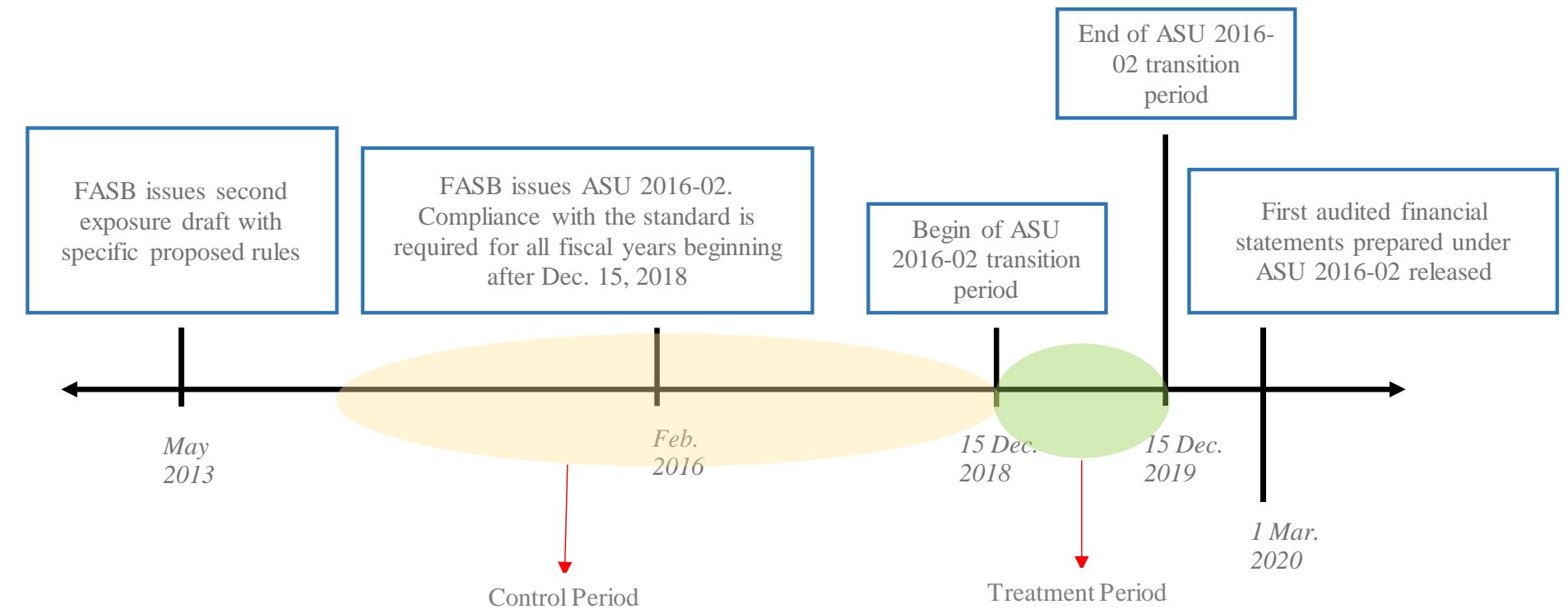

Note: This figure presents the evolution of the new leasing standard, ASC 842, through time. The portion of the timeline highlighted yellow represents the control period in our study, while the portion of the timeline highlighted green represents the treatment period in our study. 
Figure 3: Assessment of Parallel Trends

Panel A: DistanceFromEfficientInvest by lease and non-lease firms

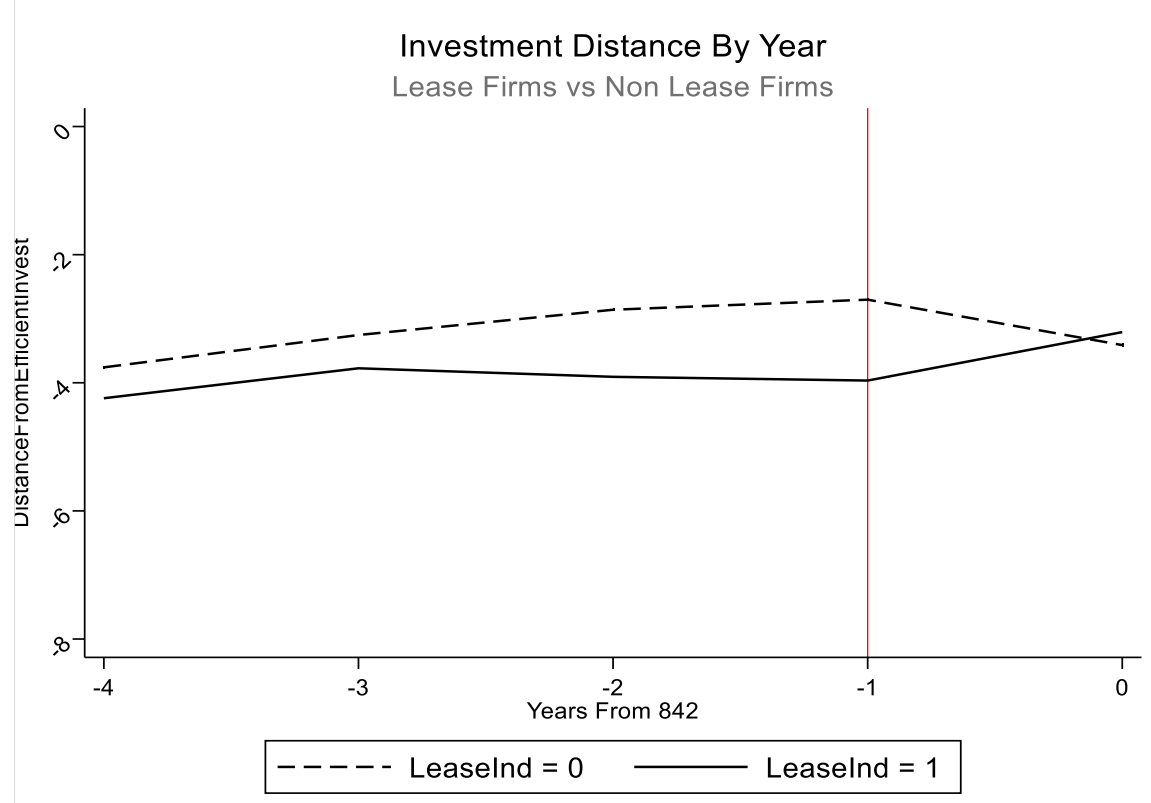

Panel B: EfficientTotalInvest by lease and non-lease firms

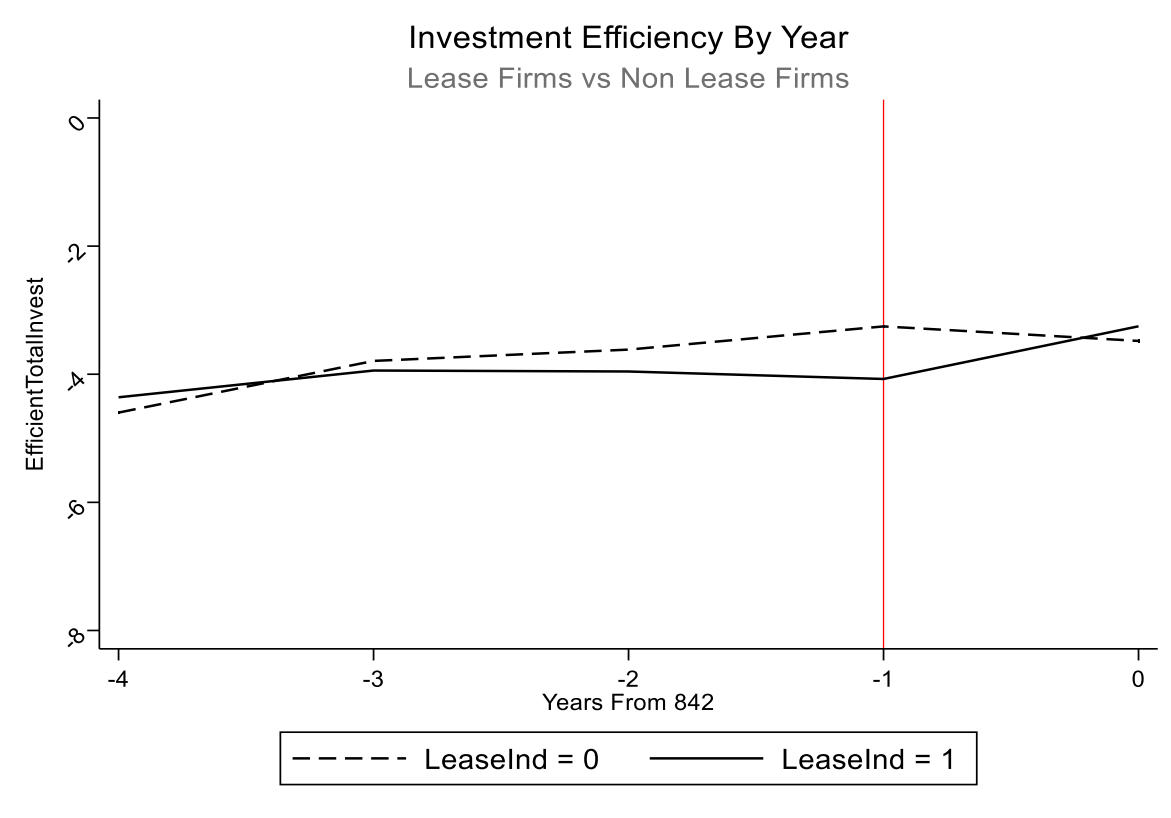




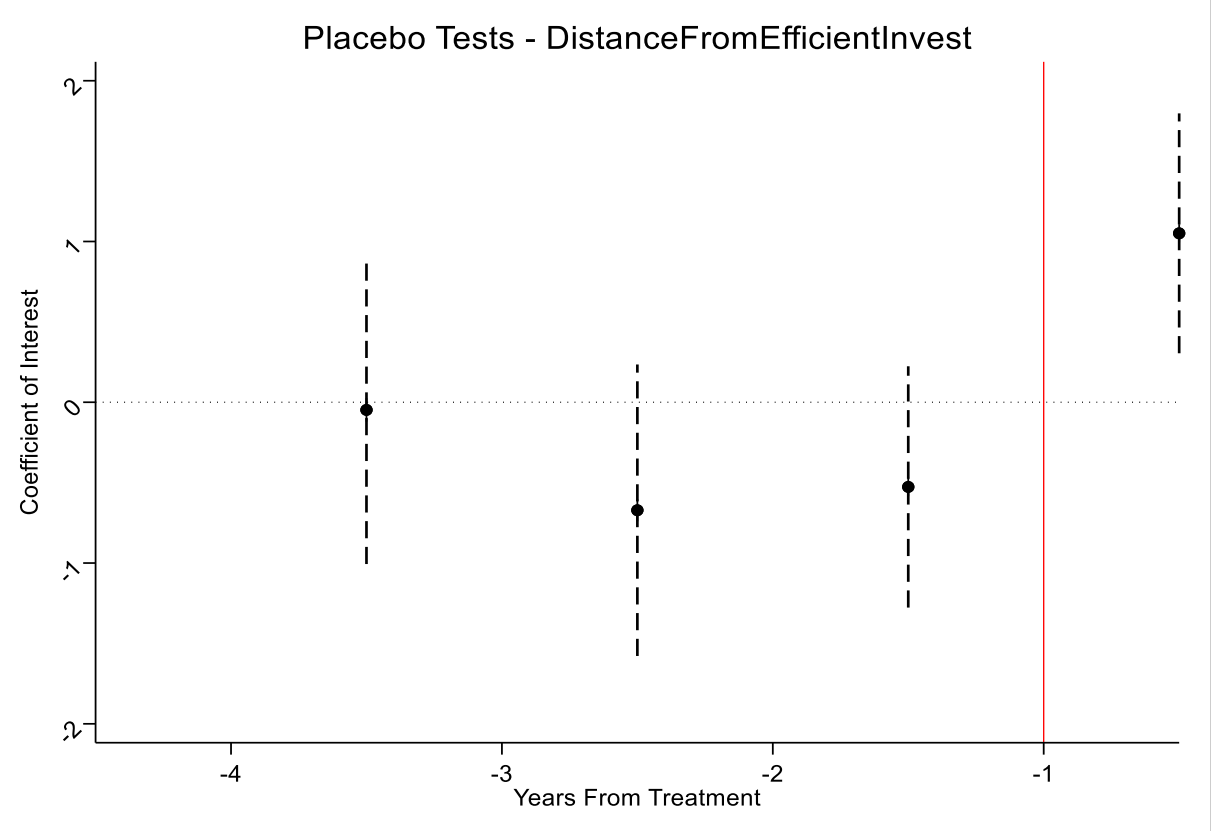

Panel D: EfficientTotalInvest statistical assessment of parallel trends

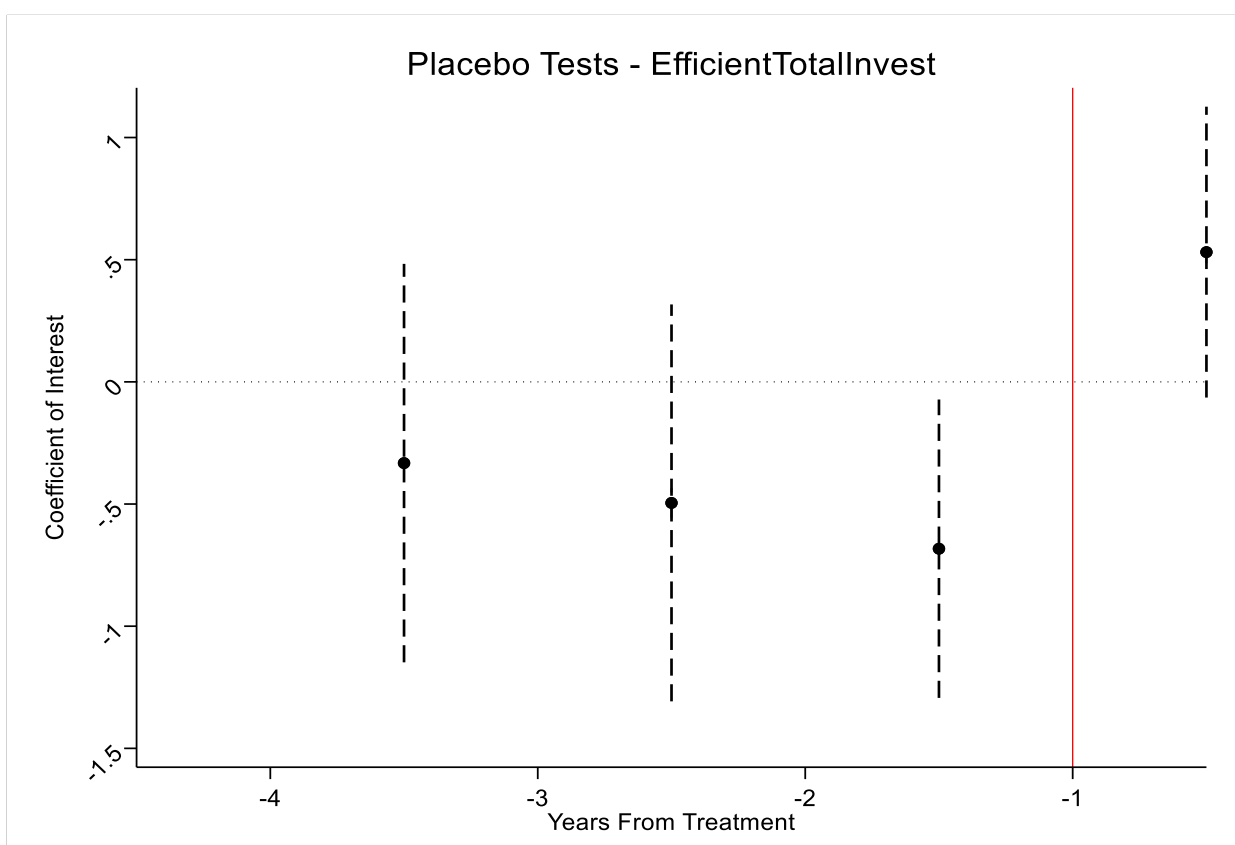

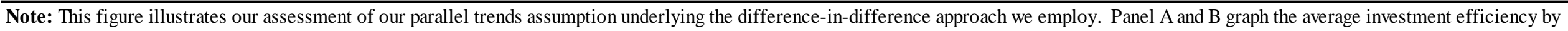
lease and non-lease firms through time in our sample period. In panel A we measure investment efficiency as DistanceFromEfficientInvest, while we measure investment efficiency as

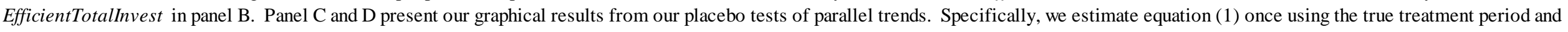

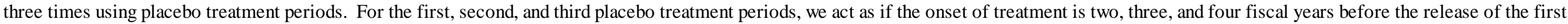

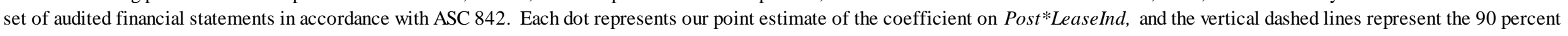

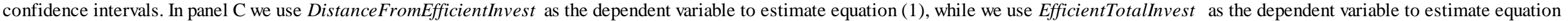
(1) in panel D. The red vertical line at negative one in all panels represents the onset of treatment in our study. 
Figure 4: External Information Environment Trends

Panel A: BidAsk by lease and non-lease firms

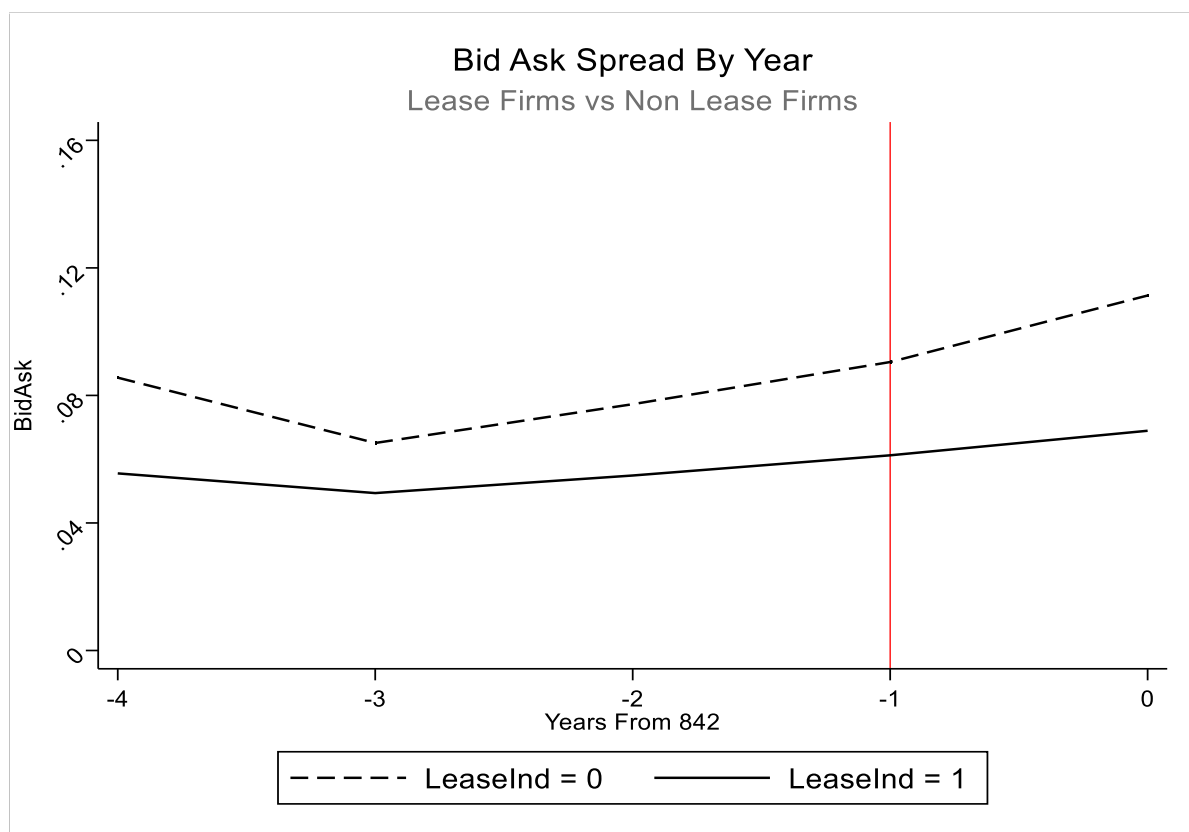

Panel B: AnalystDisp by lease and non-lease firms

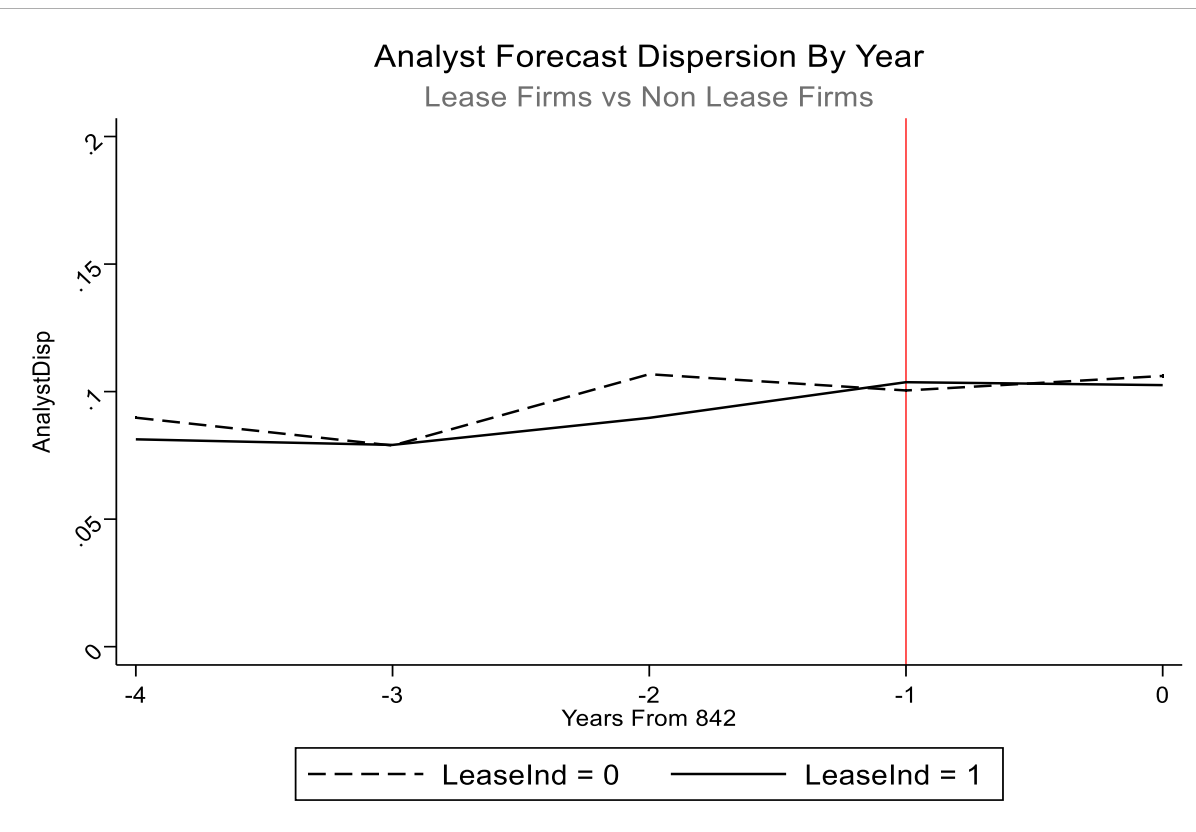




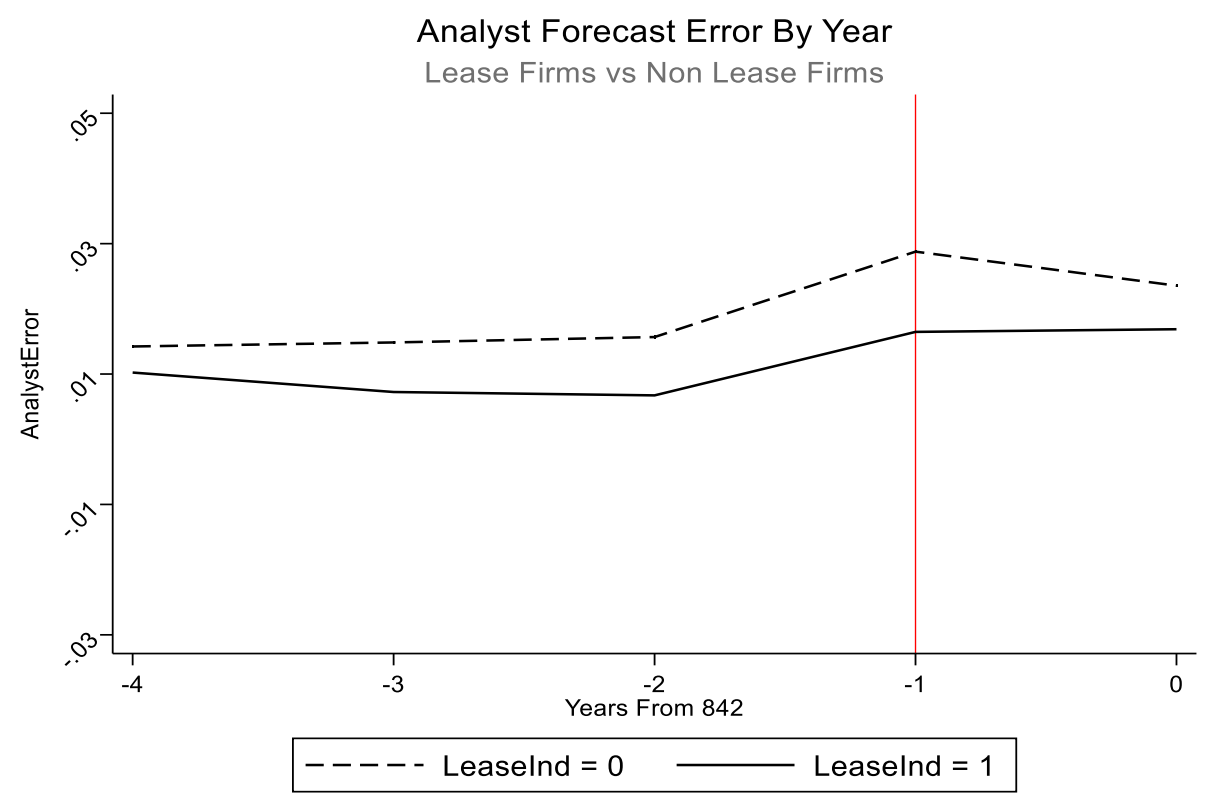

Panel D: IdioReturnVol by lease and non-lease firms

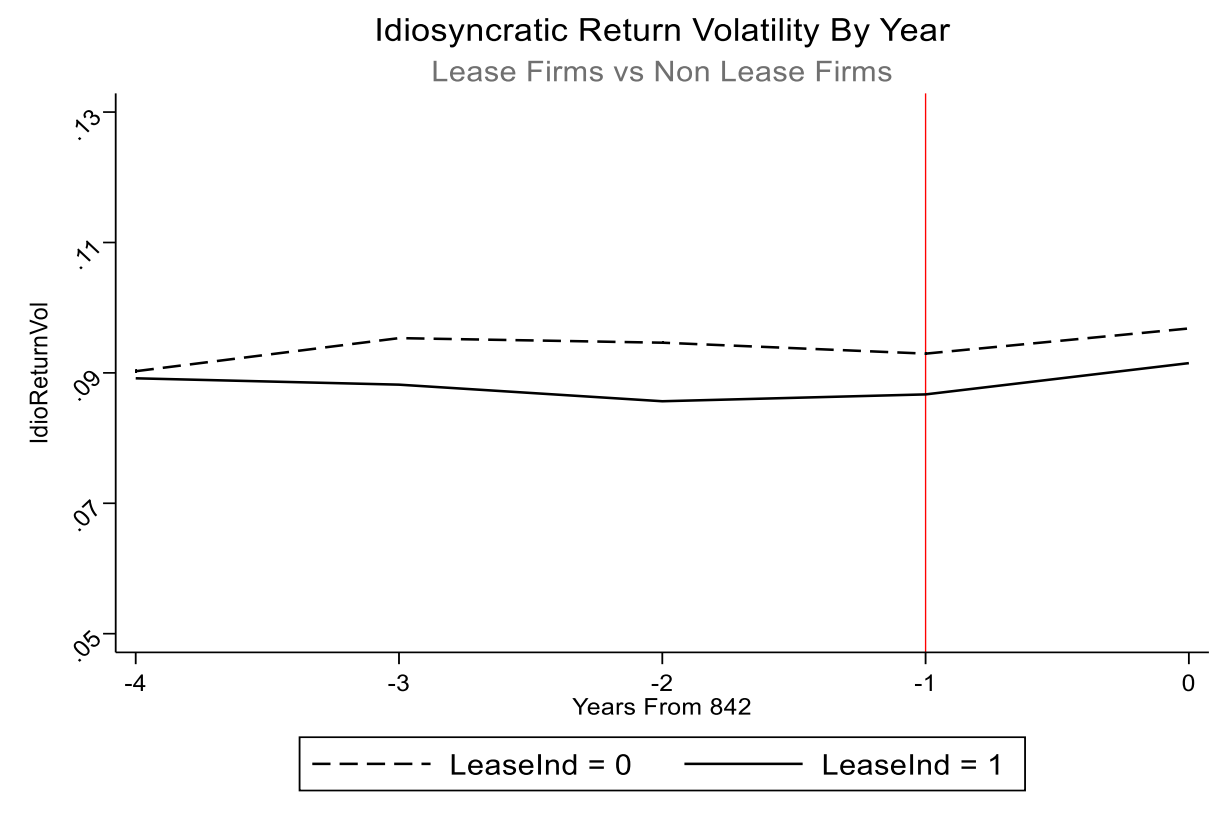




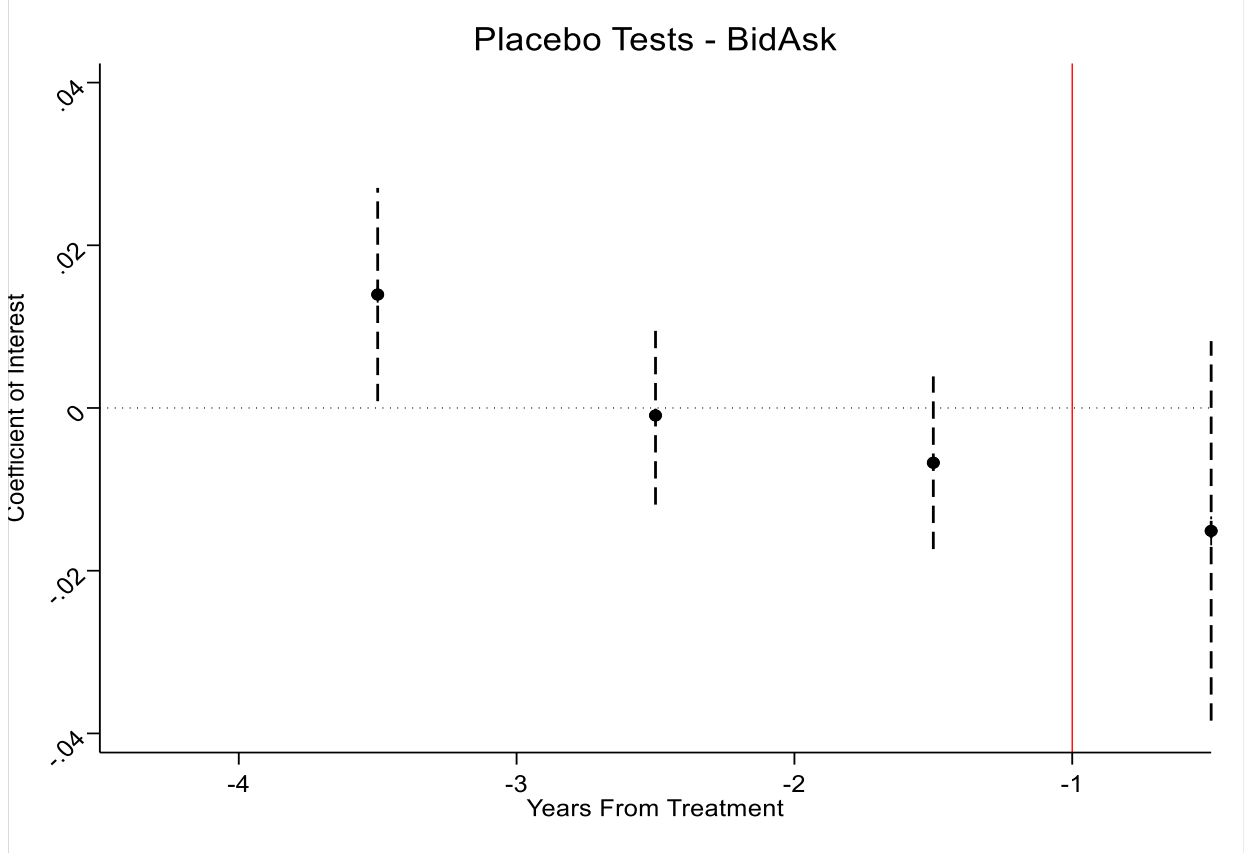

Panel F: AnalystDisp statistical assessment of parallel trends

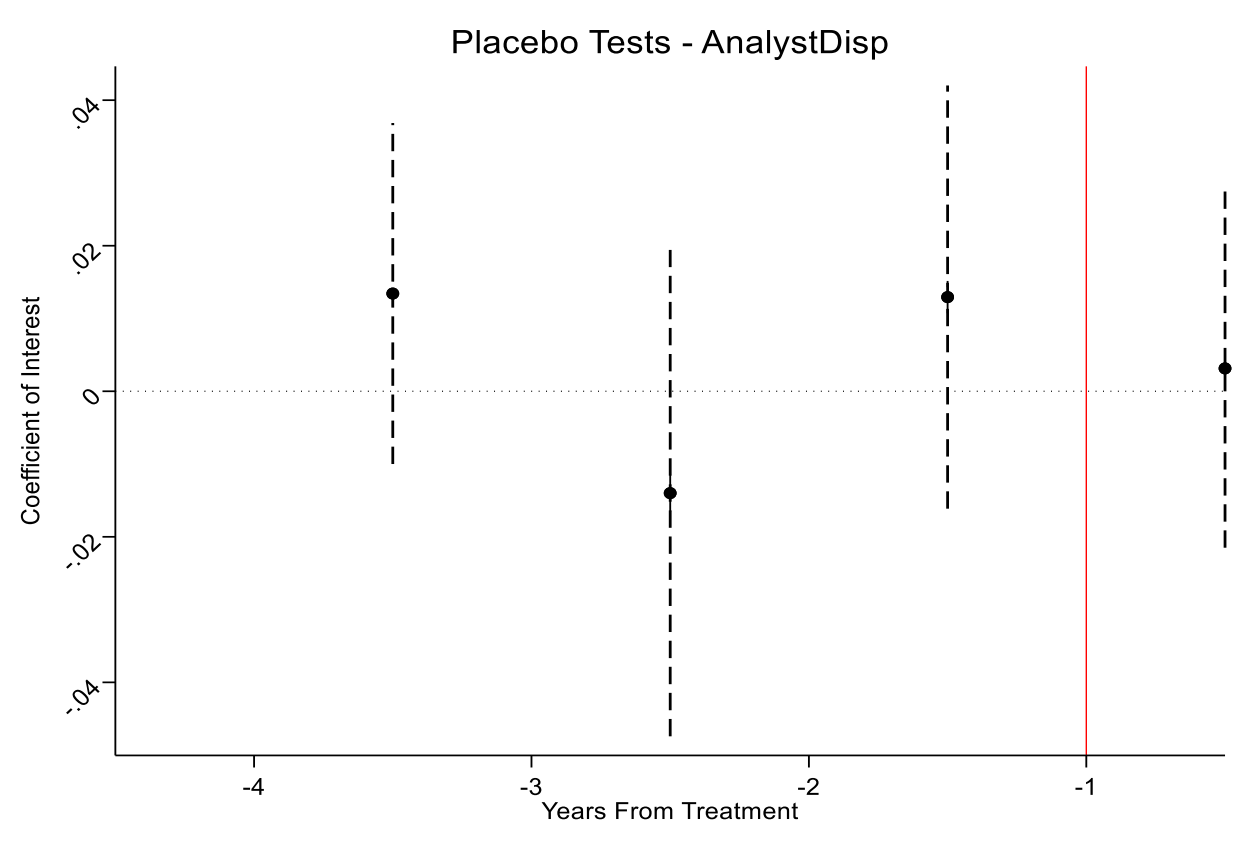




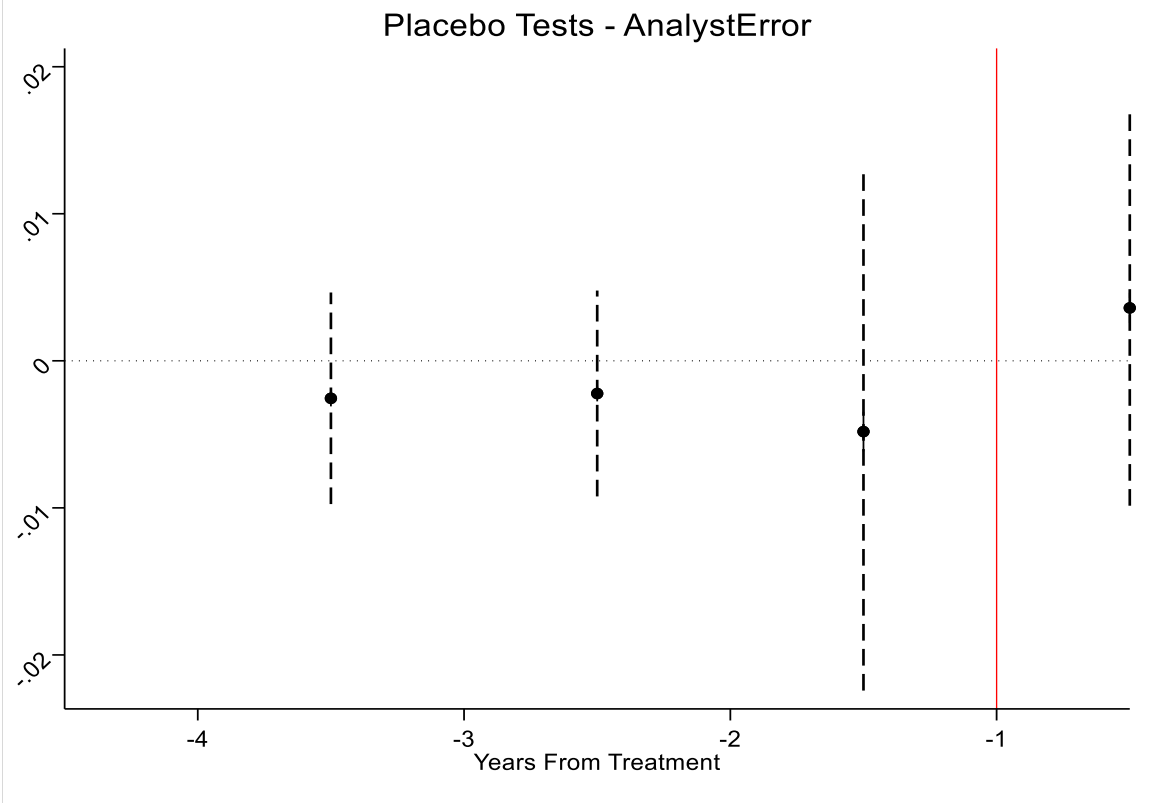

Panel H: IdioRetVol statistical assessment of parallel trends

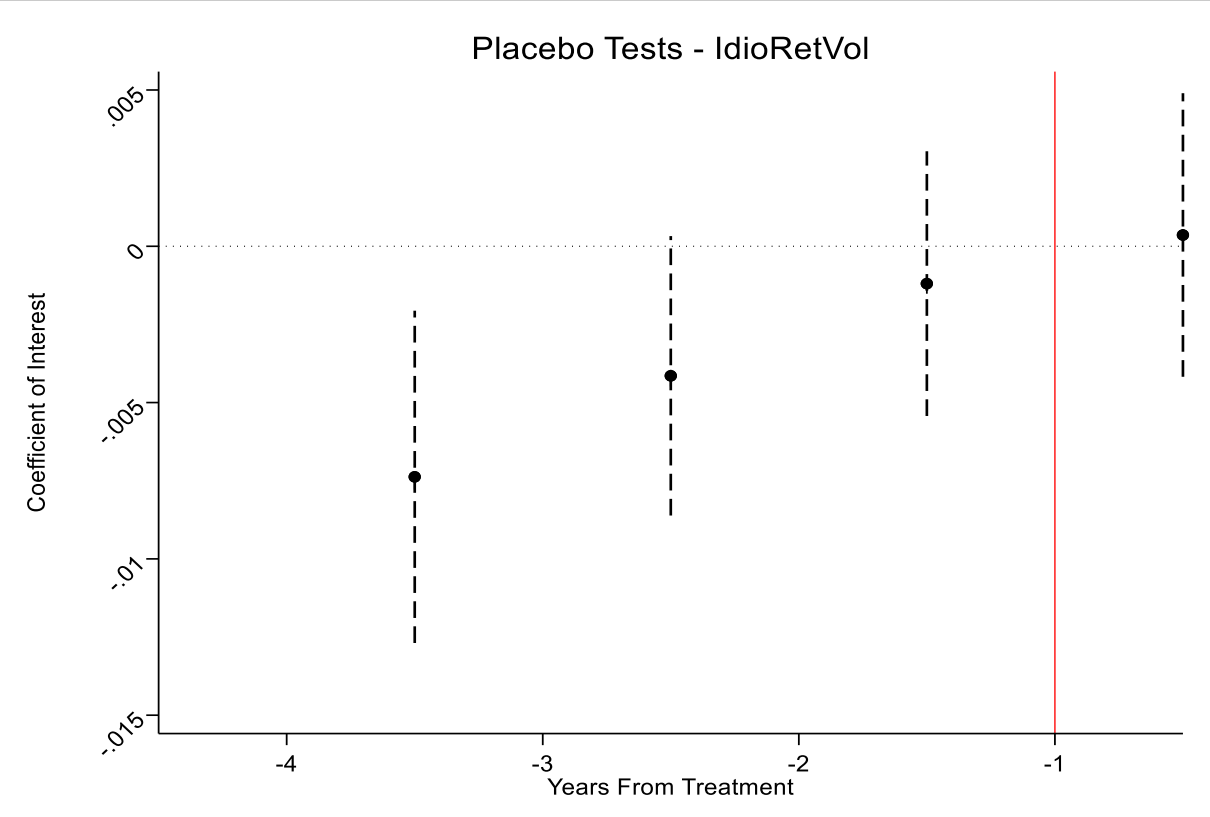

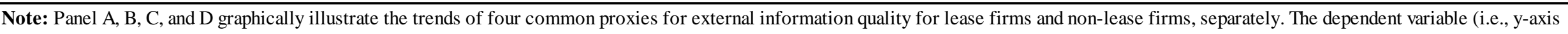

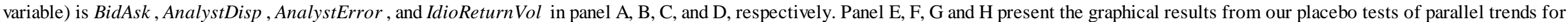

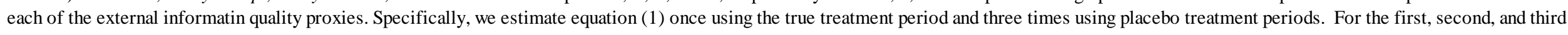

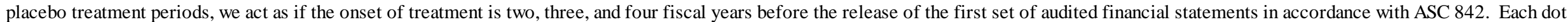

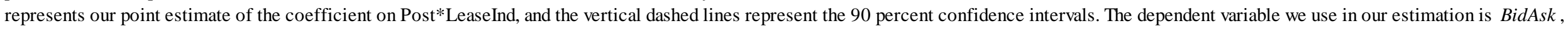
AnalystDisp , AnalystError, and IdioReturn Vol in panel E, F, G, and H, respectively. The red vertical line at negative one in all panels represents the true onset of treatment in our study. 
Figure 5: Synthetic Controls Robustness Check

Panel A: DistanceFromEfficientInvest by lease firms and non-lease synthetic control

Synthetic Controls - EfficientTotallnvest

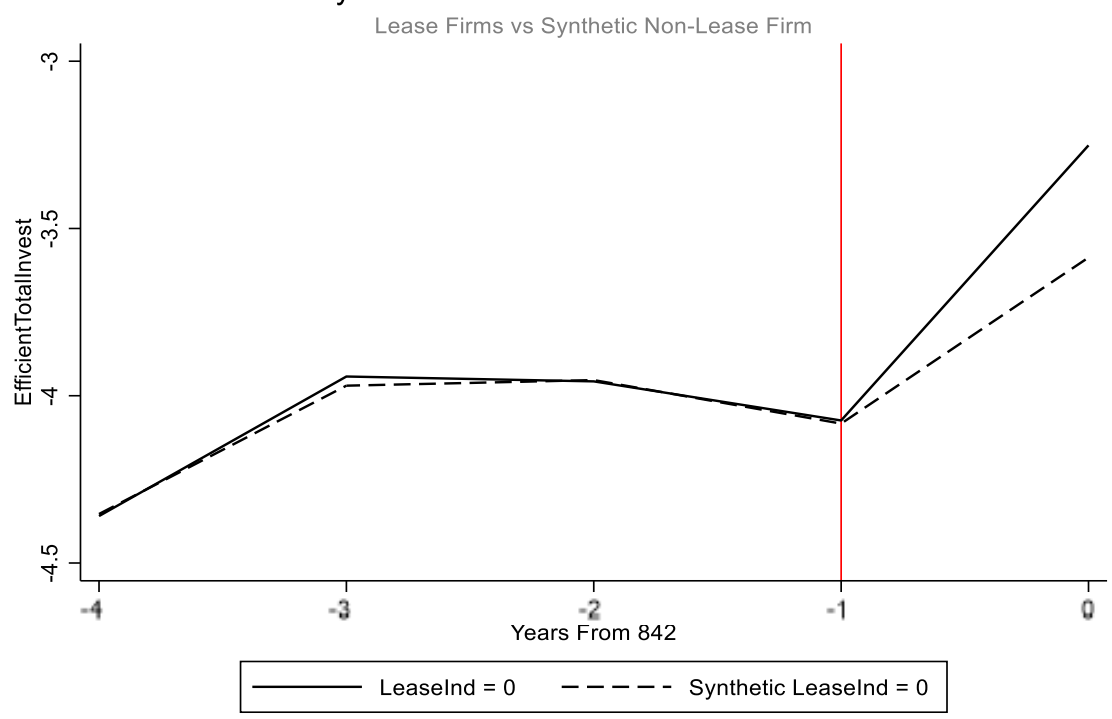

Panel B: EfficientTotalInvest by lease firms and non-lease synthetic control

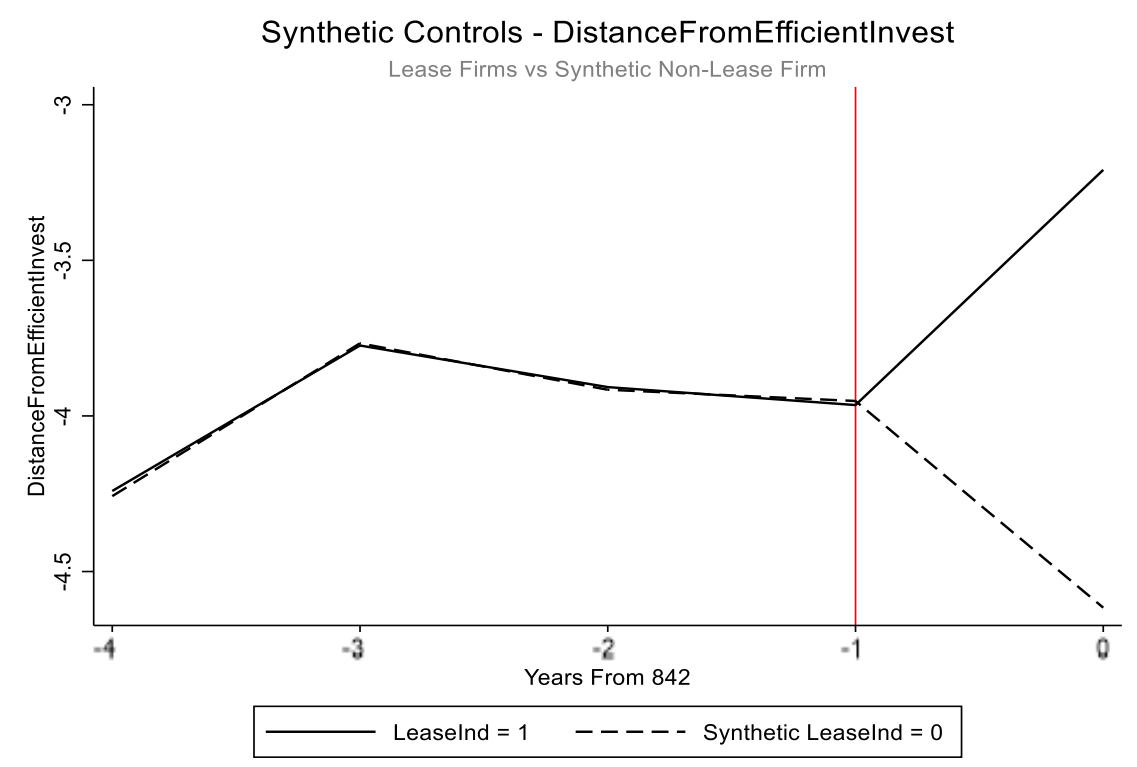

Note: This figure provides the graphical results from our synthetic controls analysis. Both panels graph the average investment efficiency by lease firms and investment efficiency for our synthetic non-lease firm through time in our sample period. In panel A we measure investment efficiency as

DistanceFromEfficientInvest, while we measure investment efficiency as EfficientTotalInvest in panel B. The red vertical line at negative one in all panels represents the onset of treatment in our study. 
Sample Size

Calcbench Universe of Firms (2015-2020)

34,298

Less: Observations missing total assets, total debt, share price, revenue, shares outstanding, cash, or operating cash flow

Less: Observations missing data necessary to create the dependent variables

Less: Observations missing data necessary to create control variables

Less: Observations relating to a firm that does not have an observation in each year of the sample Main Sample

Note: This table presents the reconciliation between the Calcbench universe of firms from 2015 to 2020 and our main sample that provides the starting point for all of our analysis. 
Table 2: Main Sample Descriptive Statistics

Panel A: Frequency distribution of lease vs non-lease observations by industry

\begin{tabular}{|c|c|c|c|c|c|}
\hline \multirow[b]{2}{*}{$S I C$} & \multicolumn{2}{|c|}{ LeaseInd $=0$} & \multicolumn{2}{|c|}{ LeaseInd $=1$} & \multirow[b]{2}{*}{ Total } \\
\hline & Freq. & $\%$ & Freq. & $\%$ & \\
\hline $1000 \mathrm{~s}$ & 25 & $6 \%$ & 370 & $94 \%$ & 395 \\
\hline $2000 s$ & 60 & $8 \%$ & 665 & $92 \%$ & 725 \\
\hline $3000 s$ & 115 & $8 \%$ & 1,270 & $92 \%$ & 1,385 \\
\hline $4000 \mathrm{~s}$ & 95 & $12 \%$ & 710 & $88 \%$ & 805 \\
\hline $5000 s$ & 20 & $3 \%$ & 620 & $97 \%$ & 640 \\
\hline $6000 s$ & 380 & $16 \%$ & 2,005 & $84 \%$ & 2,385 \\
\hline $7000 s$ & 50 & $8 \%$ & 565 & $92 \%$ & 615 \\
\hline $8000 s$ & 10 & $4 \%$ & 240 & $96 \%$ & 250 \\
\hline Total & 755 & $10 \%$ & 6,445 & $90 \%$ & 7,200 \\
\hline
\end{tabular}

Panel B: Main sample descriptive statistics

\begin{tabular}{|c|c|c|c|c|c|c|}
\hline & $\mathrm{N}$ & Mean & S.D. & Q1 & Median & Q3 \\
\hline DistanceFromEfficientInvest $_{i t}$ & 7,200 & -3.899 & 5.014 & -4.783 & -2.422 & -0.763 \\
\hline EfficientTotalInvest $_{i t}$ & 7,200 & -3.754 & 6.061 & -4.155 & -1.628 & -0.412 \\
\hline LeaseInd $_{i}$ & 7,200 & 0.895 & 0.306 & 1 & 1 & 1 \\
\hline LeaseIntensity $_{i t}$ & 7,200 & 0.0755 & 0.161 & 0.00421 & 0.0202 & 0.0650 \\
\hline CFOSales $_{i t-1}$ & 7,200 & 0.0571 & 1.024 & 0.0593 & 0.154 & 0.312 \\
\hline$\sigma C F O_{i t-1}$ & 7,200 & 0.0656 & 0.215 & 0.00878 & 0.0209 & 0.0457 \\
\hline Dividend $_{i t}$ & 7,200 & 0.642 & 0.479 & 0 & 1 & 1 \\
\hline$R O A_{i t-1}$ & 7,200 & -0.00956 & 0.316 & 0.00476 & 0.0263 & 0.0771 \\
\hline Leverage $_{i t-1}$ & 7,200 & 0.357 & 0.423 & 0.126 & 0.284 & 0.452 \\
\hline Zscore $_{i t-1}$ & 7,200 & 1.085 & 7.732 & 0.346 & 1.479 & 3.211 \\
\hline$R \& D_{i t-1}$ & 7,200 & 0.0223 & 0.0747 & 0 & 0 & 0.00604 \\
\hline Tangibility $_{i t-1}$ & 7,200 & 0.379 & 0.468 & 0.0222 & 0.180 & 0.618 \\
\hline oAccruals $_{i t-1}$ & 7,200 & 0.0817 & 0.129 & 0.0166 & 0.0387 & 0.0840 \\
\hline lnAssets $_{i t-1}$ & 7,200 & 21.67 & 2.384 & 20.52 & 21.95 & 23.22 \\
\hline AnalystFollow $_{i t}$ & 7,200 & 7.770 & 8.147 & 1 & 5 & 13 \\
\hline InstitutionalOwn $_{i t}$ & 7,200 & 0.0571 & 0.0723 & 0 & 0.0444 & 0.0675 \\
\hline Inflation $_{i t}$ & 7,200 & 0.0172 & 0.00505 & 0.0166 & 0.0200 & 0.0205 \\
\hline DefaultSpread $_{i t}$ & 7,200 & 0.943 & 0.149 & 0.873 & 0.985 & 1.049 \\
\hline RiskFree $_{i t}$ & 7,200 & 1.017 & 0.835 & 0.250 & 0.850 & 1.848 \\
\hline SalesGrowth $_{i t-1}$ & 7,200 & 0.0921 & 0.317 & -0.0126 & 0.0535 & 0.139 \\
\hline
\end{tabular}


Panel C: T-test for difference in means by lease and non-lease observations

\begin{tabular}{|c|c|c|c|c|c|c|}
\hline & \multicolumn{3}{|c|}{ LeaseInd $=1$} & \multicolumn{3}{|c|}{ LeaseInd $=0$} \\
\hline & Mean & S.D. & Median & Mean & S.D. & Median \\
\hline DistanceFromEfficientInvest $_{i t}$ & $-3.819 * * *$ & 5.041 & -2.437 & -3.197 & 4.775 & -2.356 \\
\hline EfficientTotalInvest $_{i t}$ & -3.917 & 6.131 & -1.655 & -3.748 & 5.407 & -1.362 \\
\hline CFOSales $_{i t-1}$ & $0.0780 * * *$ & 0.919 & 0.148 & -0.121 & 1.662 & 0.242 \\
\hline$\sigma C F O_{i t-1}$ & $0.0574 * * *$ & 0.185 & 0.0213 & 0.136 & 0.381 & 0.0150 \\
\hline Dividend $_{i t}$ & $0.652 * * *$ & 0.476 & 1 & 0.556 & 0.497 & 1 \\
\hline$R O A_{i t-1}$ & $0.00511 * * *$ & 0.271 & 0.0300 & -0.135 & 0.553 & 0.0119 \\
\hline Leverage $_{i t-1}$ & $0.340 * * *$ & 0.368 & 0.282 & 0.496 & 0.730 & 0.295 \\
\hline Zscore $_{i t-1}$ & $1.517 * * *$ & 6.551 & 1.609 & -2.600 & 13.74 & 0.325 \\
\hline$R \& D_{i t-1}$ & $0.0211 * * *$ & 0.0692 & 0 & 0.0323 & 0.111 & 0 \\
\hline Tangibility $_{i t-1}$ & $0.388 * * *$ & 0.468 & 0.198 & 0.300 & 0.466 & 0.0377 \\
\hline fAccruals $_{i t-1}$ & $0.0806 *$ & 0.124 & 0.0392 & 0.0912 & 0.162 & 0.0325 \\
\hline lnAssets $_{i t-1}$ & $21.80 * * *$ & 2.253 & 22.06 & 20.51 & 3.064 & 20.82 \\
\hline AnalystFollow $_{i t}$ & $8.269 * * *$ & 8.198 & 6 & 3.509 & 6.252 & 1 \\
\hline InstitutionalOwn $_{i t}$ & $0.0580 * * *$ & 0.0716 & 0.0451 & 0.0494 & 0.0777 & 0 \\
\hline Inflation $_{i t}$ & 0.0172 & 0.00506 & 0.0200 & 0.0173 & 0.00497 & 0.0200 \\
\hline DefaultSpread $_{i t}$ & 0.943 & 0.149 & 0.985 & 0.943 & 0.148 & 0.985 \\
\hline RiskFree $_{i t}$ & $1.017 * * *$ & 0.835 & 0.850 & 1.020 & 0.834 & 0.850 \\
\hline SalesGrowth $_{i t-1}$ & 0.0924 & 0.299 & 0.0541 & 0.0896 & 0.443 & 0.0467 \\
\hline
\end{tabular}

Note: This table presents descriptive and distributional statistics for our main sample. Panel A provides the frequency distribution of lease and non-lease observations by industry. We define industry by the first digit of the standard industry classification code. Panel B presents five distributional statistics for each variable we use in our analysis related to hypotheses one and two, excluding any interactions. Panel C presents the mean for each variable we use in our analysis by lease and non-lease observations. Additionally, we indicate if the difference in means is statistically significant at conventional levels using by placing asterisks next to the mean in the LeaseInd $=1-* * *, * *$, and $*$ denote significance at the 1 percent, 5 percent, and 10 percent level respectively (two-tailed). 
Table 3: Main Sample Correlations

\begin{tabular}{|c|c|c|c|c|c|c|c|c|c|c|c|c|c|c|c|c|c|c|c|c|}
\hline & (1) & (2) & (3) & (4) & $(5)$ & (6) & (7) & (8) & (9) & $(10)$ & (11) & $(12)$ & (13) & $(14)$ & $(15)$ & $(16)$ & $(17)$ & $(18)$ & (19) & $(20)$ \\
\hline (1) DistanceFromEfficientInvest ${ }_{i t}$ & 1.00 & & & & & & & & & & & & & & & & & & & \\
\hline (2) EfficientTotalInvest ${ }_{i t}$ & $0.92 *$ & 1.00 & & & & & & & & & & & & & & & & & & \\
\hline (3) LeaseInd $i t$ & $-0.03 *$ & -0.01 & 1.00 & & & & & & & & & & & & & & & & & \\
\hline (4) LeaseIntensity ${ }_{i t}$ & $-0.08 *$ & $-0.08 *$ & $0.15^{*}$ & 1.00 & & & & & & & & & & & & & & & & \\
\hline (5) CFOSales ${ }_{i t-1}$ & $0.02 *$ & $0.05 *$ & $0.06 *$ & $-0.07 *$ & 1.00 & & & & & & & & & & & & & & & \\
\hline (6) $\sigma C F O_{i t-1}$ & $-0.04 *$ & $-0.08 *$ & $-0.11 *$ & $0.09 *$ & $-0.46 *$ & 1.00 & & & & & & & & & & & & & & \\
\hline (7) Dividend ${ }_{i t}$ & $0.13 *$ & $0.16^{*}$ & $0.06 *$ & $-0.09 *$ & $0.20 *$ & $-0.22 *$ & 1.00 & & & & & & & & & & & & & \\
\hline (8) $R O A_{i t-1}$ & 0.01 & $0.04 *$ & $0.14 *$ & $-0.06 *$ & $0.48 *$ & $-0.65 *$ & $0.23 *$ & 1.00 & & & & & & & & & & & & \\
\hline (9) Leverage ${ }_{i t-1}$ & $-0.07 *$ & $-0.10 *$ & $-0.11 *$ & $0.12 *$ & $-0.27 *$ & $0.43 *$ & $-0.16^{*}$ & $-0.47 *$ & * 1.00 & & & & & & & & & & & \\
\hline (10) Zscore $_{i t-1}$ & $-0.04 *$ & 0.00 & $0.16^{*}$ & $-0.04 *$ & $0.38 *$ & $-0.56 *$ & $0.14^{*}$ & $0.70 *$ & $-0.63 *$ & 1.00 & & & & & & & & & & \\
\hline (11) $R \& D_{i t-1}$ & -0.02 & $-0.05 *$ & $-0.05 *$ & $0.07^{*}$ & $-0.46 *$ & $0.42 *$ & $-0.26 *$ & $-0.46 *$ & $0.24 *$ & $-0.32 *$ & 1.00 & & & & & & & & & \\
\hline (12) Tangibility ${ }_{i t-1}$ & $-0.14 *$ & $-0.13 *$ & $0.06^{*}$ & $0.20 *$ & $-0.02 *$ & $0.03 *$ & $-0.11^{*}$ & $-0.02 *$ & $0.16^{*}$ & $-0.04 *$ & 0.02 & 1.00 & & & & & & & & \\
\hline (13) $\sigma$ Accruals $_{i t-1}$ & $-0.07 *$ & $-0.11 *$ & $-0.03 *$ & $0.09 *$ & $-0.23 *$ & $0.40 *$ & $-0.27 *$ & $-0.31 *$ & $0.23 *$ & $-0.23 *$ & $0.34 *$ & $-0.02 *$ & 1.00 & & & & & & & \\
\hline (14) InAssets ${ }_{i t-1}$ & $0.14 *$ & $0.18 *$ & $0.17 *$ & $-0.16 *$ & $0.32 *$ & $-0.44 *$ & $0.45^{*}$ & $0.42 *$ & ${ }^{k}-0.28 *$ & $0.38 *$ & $-0.32 *$ & $-0.12 *$ & $-0.36^{*}$ & 1.00 & & & & & & \\
\hline (15) AnalystFollow ${ }_{i t}$ & -0.02 & 0.00 & $0.18 *$ & $-0.03 *$ & $0.09 *$ & $-0.14 *$ & $0.17^{*}$ & 0.18 * & * $-0.09 *$ & $0.19 *$ & $-0.05^{*}$ & $0.11 *$ & $-0.07 *$ & $0.57 *$ & 1.00 & & & & & \\
\hline (16) InstitutionalOwn $n_{i t}$ & -0.01 & -0.01 & $0.04 *$ & $-0.03 *$ & $-0.03 *$ & $-0.04 *$ & -0.02 & 0.00 & $-0.04 *$ & $0.05 *$ & $0.03 *$ & $0.02 *$ & 0.00 & -0.01 & $-0.04 *$ & 1.00 & & & & \\
\hline (17) Inflation $_{i t}$ & $0.03 *$ & $0.03 *$ & 0.00 & -0.02 & $0.06 *$ & 0.00 & 0.01 & $-0.04 *$ & * $0.04 *$ & $-0.04 *$ & $0.01 *$ & 0.01 & 0.00 & $0.03 *$ & -0.01 & 0.00 & 1.00 & & & \\
\hline (18) DefaultSpread ${ }_{i t}$ & -0.01 & -0.01 & 0.00 & 0.00 & $-0.04 *$ & $=0.00$ & 0.00 & $0.02 *$ & ${ }^{k}-0.03 *$ & $0.02 *$ & $0.00 *$ & -0.01 & $0.02 *$ & -0.01 & 0.01 & $0.04 *$ & $-0.63 *$ & 1.00 & & \\
\hline (19) RiskFree ${ }_{i t}$ & $0.04 *$ & $0.05 *$ & 0.00 & -0.02 & $0.05 *$ & 0.00 & 0.00 & -0.02 & 0.00 & -0.02 & $0.01 *$ & 0.01 & $0.09 *$ & $0.03 *$ & $-0.03 *$ & $0.14^{*}$ & $0.40^{*}$ & $-0.34 *$ & 1.00 & \\
\hline (20) SalesGrowth ${ }_{i t-1}$ & $-0.03 *$ & $-0.03 *$ & 0.00 & 0.01 & 0.01 & $0.16 *$ & $-0.08 *$ & $-0.07 *$ & * $\quad 0.04 *$ & 0.00 & $0.09 *$ & $-0.10 *$ & $0.08 *$ & $-0.07 *$ & $-0.02 *$ & $0.02 *$ & $-0.06 *$ & $0.03 *$ & $0.03 *$ & 1.00 \\
\hline
\end{tabular}

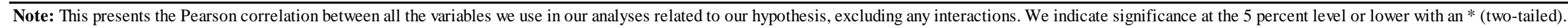


Table 4: Test of Hypothesis One - On Average Analysis

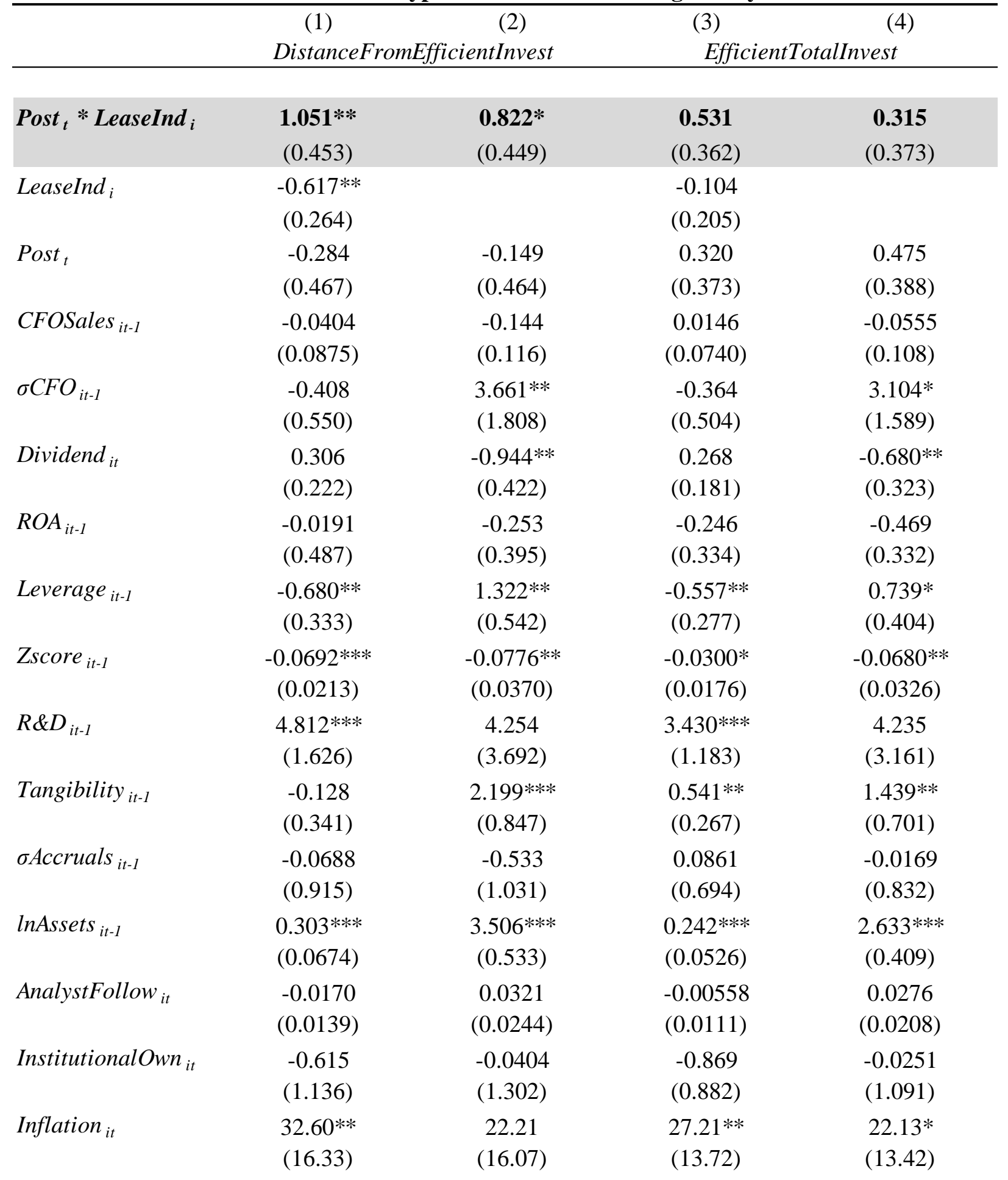




\begin{tabular}{lcccc} 
DefaultSpread $_{i t}$ & 0.244 & 0.322 & -0.0427 & -0.0429 \\
& $(0.626)$ & $(0.615)$ & $(0.520)$ & $(0.510)$ \\
RiskFree $_{i t}$ & -0.0397 & $-0.284 * *$ & -0.0204 & $-0.236^{* *}$ \\
& $(0.130)$ & $(0.134)$ & $(0.105)$ & $(0.109)$ \\
SalesGrowth $_{\text {it- } 1}$ & & & -0.305 & 0.310 \\
& & & $(0.235)$ & $(0.259)$ \\
Constant & $-10.38^{* * *}$ & $-81.39 * * *$ & $-9.707 * * *$ & $-62.04 * * *$ \\
& $(1.589)$ & $(11.41)$ & $(1.263)$ & $(8.783)$ \\
Industry FE & & & & \\
Firm FE & YES & NO & YES & NO \\
Observations & NO & YES & NO & YES \\
Adjusted R-squared & 7,200 & 7,200 & 7,200 & 7,200 \\
\hline Nite: Thi tren & 0.099 & 0.272 & 0.141 & 0.275 \\
\hline
\end{tabular}

Note: This table presents the results from estimating equation (1) using ordinary least squares regression. We provide our point estimate for each coefficient and its associated standard errors (in parentheses). For columns 1 and 2, the dependent variable is DistanceFromEfficientInvest. For columns 3 and 4, the dependent variable is

EfficientTotalInvest. Columns 1 and 3 include industry fixed effects where we define industry using the Fama French 48 industry classification. Columns 2 and 4 include firm fixed effects. For all specifications, we cluster our standard errors by firm. $* * *,{ }^{* *}$, and $*$ denote significance at the 1 percent, 5 percent, and 10 percent level respectively (twotailed). 
Table 5: Test of Hypothesis One - Lease Intensity Analysis

Panel A: Lease and non-lease firms

(2)

(3)

(4)

DistanceFromEfficientInvest

EfficientTotalInvest

\begin{tabular}{|c|c|c|c|c|}
\hline \multirow[t]{2}{*}{ Post $_{t} *$ Lease Rank $_{i 10}$} & $2.262 * * *$ & $2.139 * * *$ & $1.244 * *$ & $1.178 * *$ \\
\hline & $(0.609)$ & $(0.622)$ & $(0.497)$ & $(0.507)$ \\
\hline \multirow[t]{2}{*}{ Post $_{t} *$ LeaseRank $_{i 9}$} & $1.549 * *$ & $1.448 * *$ & $0.971 *$ & 0.827 \\
\hline & $(0.686)$ & $(0.673)$ & $(0.557)$ & $(0.560)$ \\
\hline \multirow{2}{*}{ Post $_{t} *$ LeaseRank $_{i 8}$} & $1.474 * *$ & $1.362 * *$ & 0.773 & 0.627 \\
\hline & $(0.677)$ & $(0.661)$ & $(0.544)$ & $(0.548)$ \\
\hline \multirow[t]{2}{*}{ Post $_{t} *$ LeaseRank $_{i 7}$} & 0.925 & 0.604 & 0.400 & 0.0892 \\
\hline & $(0.676)$ & $(0.675)$ & $(0.560)$ & $(0.567)$ \\
\hline \multirow[t]{2}{*}{ Post $_{t} *$ LeaseRank $_{i 6}$} & 0.597 & 0.460 & 0.255 & 0.0889 \\
\hline & $(0.683)$ & $(0.676)$ & $(0.560)$ & $(0.568)$ \\
\hline \multirow[t]{2}{*}{ Post $_{t} *$ LeaseRank $_{i 5}$} & 0.478 & 0.334 & 0.227 & 0.0909 \\
\hline & $(0.661)$ & $(0.659)$ & $(0.555)$ & $(0.564)$ \\
\hline \multirow[t]{2}{*}{ Post $_{t} *$ LeaseRank $_{i 4}$} & 1.162 & 0.827 & 0.864 & 0.562 \\
\hline & $(0.714)$ & $(0.686)$ & $(0.574)$ & $(0.564)$ \\
\hline \multirow[t]{2}{*}{ Post $_{t} *$ LeaseRank $_{i 3}$} & 0.832 & 0.491 & 0.313 & 0.0155 \\
\hline & $(0.569)$ & $(0.560)$ & $(0.470)$ & $(0.476)$ \\
\hline \multirow[t]{2}{*}{ Post $_{t} *$ LeaseRank $_{i 2}$} & 0.793 & 0.469 & 0.401 & 0.115 \\
\hline & $(0.482)$ & $(0.479)$ & $(0.416)$ & $(0.426)$ \\
\hline \multirow[t]{2}{*}{ Post $_{t} *$ LeaseRank $_{i 1}$} & 0.435 & 0.0380 & -0.162 & -0.489 \\
\hline & $(0.585)$ & $(0.586)$ & $(0.464)$ & $(0.474)$ \\
\hline Main Effects & YES & YES & YES & YES \\
\hline Control Variables & YES & YES & YES & YES \\
\hline Industry FE & YES & NO & YES & NO \\
\hline Firm FE & NO & YES & NO & YES \\
\hline Observations & 7,200 & 7,200 & 7,200 & 7,200 \\
\hline Adjusted R-squared & 0.099 & 0.272 & 0.142 & 0.275 \\
\hline
\end{tabular}


Panel B: Lease firms only

(2)

(3)

(4)

DistanceFromEfficientInvest

EfficientTotalInvest

\begin{tabular}{|c|c|c|c|c|}
\hline \multirow[t]{2}{*}{ Post $_{t} *$ LeaseRank $_{i 10}$} & $1.803 * * *$ & $2.130 * * *$ & $1.388 * * *$ & $1.712 * * *$ \\
\hline & $(0.589)$ & $(0.609)$ & $(0.482)$ & $(0.489)$ \\
\hline \multirow{2}{*}{ Post $_{t} *$ LeaseRank $_{i 9}$} & $1.100 *$ & $1.439 * *$ & $1.129 * *$ & $1.351 * *$ \\
\hline & $(0.666)$ & $(0.659)$ & $(0.540)$ & $(0.536)$ \\
\hline \multirow{2}{*}{ Post $_{t} *$ LeaseRank $_{i 8}$} & 1.044 & $1.338 * *$ & $0.943 *$ & $1.132 * *$ \\
\hline & $(0.661)$ & $(0.656)$ & $(0.531)$ & $(0.529)$ \\
\hline \multirow{2}{*}{ Post $_{t} *$ LeaseRank $_{i 7}$} & 0.507 & 0.577 & 0.576 & 0.580 \\
\hline & $(0.662)$ & $(0.668)$ & $(0.548)$ & $(0.547)$ \\
\hline \multirow[t]{2}{*}{ Post $_{t} *$ LeaseRank $_{i 6}$} & 0.153 & 0.444 & 0.419 & 0.619 \\
\hline & $(0.667)$ & $(0.666)$ & $(0.546)$ & $(0.547)$ \\
\hline \multirow[t]{2}{*}{ Post $_{t} *$ LeaseRank $_{i 5}$} & 0.0547 & 0.283 & 0.394 & 0.561 \\
\hline & $(0.645)$ & $(0.652)$ & $(0.543)$ & $(0.544)$ \\
\hline \multirow{2}{*}{ Post $_{t} *$ LeaseRank $_{i 4}$} & 0.734 & 0.793 & $1.030^{*}$ & $1.056^{*}$ \\
\hline & $(0.698)$ & $(0.678)$ & $(0.563)$ & $(0.546)$ \\
\hline \multirow[t]{2}{*}{ Post $_{t} *$ LeaseRank $_{i 3}$} & 0.406 & 0.464 & 0.481 & 0.512 \\
\hline & $(0.554)$ & $(0.551)$ & $(0.459)$ & $(0.455)$ \\
\hline \multirow[t]{2}{*}{ Post $_{t} *$ LeaseRank $_{i 2}$} & 0.351 & 0.433 & 0.558 & 0.607 \\
\hline & $(0.467)$ & $(0.473)$ & $(0.405)$ & $(0.404)$ \\
\hline Main Effects & YES & YES & YES & YES \\
\hline Control Variables & YES & YES & YES & YES \\
\hline Industry FE & YES & NO & YES & NO \\
\hline Firm FE & NO & YES & NO & YES \\
\hline Observations & 7,200 & 7,200 & 7,200 & 7,200 \\
\hline Adjusted R-squared & 0.099 & 0.272 & 0.133 & 0.273 \\
\hline
\end{tabular}

Note: This table presents the results from estimating equation (5) using ordinary least squares regression. Panel A presents the results from estimation in the sample with both lease and non-lease firms. Panel B presents the results from estimation in the sample with only lease firms. We provide our point estimate for each coefficient and its associated standard errors (in parentheses). We omit our estimates of the coefficients for the control variables included in equation (5) and main effects. Columns 1 and 2 relate to our estimates using DistanceFromEfficientInvest as the dependent variable, while columns 3 and 4 relate to our estimates using EfficientTotalInvest as the dependent variable. Columns 1 and 3 include industry fixed effects where we define industry using the Fama French 48 industry classification. Columns 2 and 4 include firm fixed effects. For all specifications, we cluster our standard errors by firm. ***, **, and * denote significance at the 1 percent, 5 percent, and 10 percent level respectively (two-tailed). 
Table 6: EIQ Analysis

\begin{tabular}{lcccc}
\hline & $(1)$ & $(2)$ & $(3)$ & $(4)$ \\
& BidAsk & AnalystDisp & AnalystError & IdioReturnVol \\
\hline & & & & \\
Post $_{\boldsymbol{t}}$ * $^{\text {LeaseInd }} \boldsymbol{i}_{\boldsymbol{i}}$ & $\mathbf{- 0 . 0 1 5 1}$ & $\mathbf{0 . 0 0 3 1 4}$ & $\mathbf{0 . 0 0 3 6 0}$ & $\mathbf{0 . 0 0 0 3 6 1}$ \\
& $(0.0142)$ & $(0.0150)$ & $(0.00817)$ & $(0.00275)$ \\
& & & & \\
Main Effects & YES & YES & YES & YES \\
Controls & YES & YES & YES & YES \\
Industry FE & YES & YES & YES & YES \\
Firm FE & NO & NO & NO & NO \\
Observations & 5,990 & 4,045 & 4,460 & 5,160 \\
Adjusted R-squared & 0.129 & 0.134 & 0.105 & 0.558 \\
\hline
\end{tabular}

Note: This table presents the results from estimating equation (1) using ordinary least squares regression after replacing our investment efficiency dependent variables with external information environment quality variables and updating control variables accordingly. We provide our point estimate for each coefficient and it's associated standard errors (in parantheses). For columns 1, 2, 3, and 4 the dependent variable is BidAsk, AnalystDisp, AnalystError, and IdioReturn Vol, respectively. We provide our point estimate for each coefficient and its associated standard errors (in parentheses). We omit our estimates of the coefficients for the control variables. For all specifications, we include industry fixed effects defined by the Fama French 48 industry classification and cluster our standard errors by firm. ***, **, and * denote significance at the 1 percent, 5 percent, and 10 percent level respectively (two-tailed). 
Table 7: Operating Segment Analysis

Panel A: Multiple segment firms only

DistanceFromEfficientInvest

Post $_{t}$ * LeaseInd

$1.497 * *$

$1.228^{*}$

$\mathbf{0 . 7 3 0}$

0.497

(0.730)

(0.686)

$(0.581)$

(0.581)

Main Effects
Control Variables
Industry FE
Firm FE

YES

YES

YES

YES

YES

YES

YES

NO

YES

YES

Firm FE

NO

YES

YES

NO

Observations

5,795

5,795

NO

YES

Adjusted R-squared

0.086

0.261

5,795

5,795

Panel B: Single segment firms only
(1)
(2)
(3)

0.118

0.248

(4)

DistanceFromEfficientInvest

EfficientTotalInvest

Post $_{t} *$ LeaseInd $_{i}$

$-0.178$

$(0.550)$

Main Effects

Control Variables

Industry FE

Firm FE

Observations

Adjusted R-squared

$\begin{array}{cc}\text { YES } & \text { YES } \\ \text { YES } & \text { YES } \\ \text { YES } & \text { NO } \\ \text { NO } & \text { YES } \\ 1,405 & 1,405 \\ 0.208 & 0.378\end{array}$

$-\mathbf{0 . 2 4 8}$

$(0.430)$

$\mathbf{- 0 . 1 2 6}$
$(0.553)$

0.378

$\begin{array}{cc}\text { YES } & \text { YES } \\ \text { YES } & \text { YES } \\ \text { YES } & \text { NO } \\ \text { NO } & \text { YES } \\ 1,405 & 1,405 \\ 0.327 & 0.479\end{array}$

$-0.232$

(0.438)

YES

NO

Note: This table presents the results from estimating equation (1) using ordinary least squares regression. Panel A presents the results from estimation in the sample of firms with multiple operating segments only. Panel B presents the results from estimation in the sample of firms with a single operating segment. For columns 1 and 2 , the dependent variable is DistanceFromEfficientInvest, while the dependent variable is EfficientTotalInvest for columns 3 and 4 . We provide our point estimate for each coefficient and its associated standard errors (in parentheses). We omit our estimates of the coefficients for the control variables and main effects. Columns 1 and 3 include industry fixed effects where we define industry using the Fama French 48 industry classification. Columns 2 and 4 include firm fixed effects. For all specifications, we cluster our standard errors by firm. ${ }^{* * *},{ }^{* *}$, and $*$ denote significance at the 1 percent, 5 percent, and 10 percent level respectively (two-tailed). 
Table 8: Internal Information Asymmetry Analysis

\begin{tabular}{lcccc}
\hline & $(1)$ & $(2)$ & $(3)$ & $(4)$ \\
& DistanceFromEfficientInvest & \multicolumn{2}{c}{ EfficientTotalInvest } \\
\hline Post $_{\boldsymbol{t}}$ * DivAdvantage $_{\boldsymbol{i}}$ & $\mathbf{1 . 1 4 8}$ & $\mathbf{1 . 5 4 3}$ & $\mathbf{1 . 2 6 3}$ & $\mathbf{1 . 6 1 3} * *$ \\
& $(1.005)$ & $(0.930)$ & $(0.825)$ & $(0.774)$ \\
& & & & \\
Main Effects & YES & YES & YES & YES \\
Control Variables & YES & YES & YES & YES \\
Industry FE & YES & NO & YES & NO \\
Firm FE & NO & YES & NO & YES \\
Observations & 710 & 710 & 710 & 710 \\
Adjusted R-squared & 0.059 & 0.185 & 0.048 & 0.164 \\
\hline
\end{tabular}

Note: This table presents the results from estimating equation (6) using ordinary least squares regression. For columns 1 and 2, the dependent variable is DistanceFromEfficientInvest, while the dependent variable is EfficientTotalInvest for columns 3 and 4. We provide our point estimate for each coefficient and its associated standard errors (in parentheses). We omit our estimates of the coefficients for the control variables and main effects. Columns 1 and 3 include industry fixed effects where we define industry using the Fama French 48 industry classification. Columns 2 and 4 include firm fixed effects. For all specifications, we cluster our standard errors by firm. $* * * * *$, and $*$ denote significance at the 1 percent, 5 percent, and 10 percent level respectively (two-tailed). 
Table 9: Over- and Under-Investors Analysis

Panel A: Under-investing sample regression results

Under-Firm Sample

\begin{tabular}{lcccc}
\cline { 2 - 4 } & \multicolumn{3}{c}{ DistanceFromEfficientInvest } & \multicolumn{2}{c}{ EfficientTotalinvest } \\
\hline Post $_{\boldsymbol{t}} \boldsymbol{*}^{\text {LeaseInd }} \boldsymbol{i}_{\boldsymbol{i}}$ & $\mathbf{0 . 9 7 9}$ & $\mathbf{0 . 9 2 3}$ & $\mathbf{0 . 0 2 3 6}$ & $\mathbf{- 0 . 0 1 9 3}$ \\
& $(0.667)$ & $(0.577)$ & $(0.391)$ & $(0.376)$ \\
Main Effects & & & \\
Control Variables & YES & YES & YES & YES \\
Industry FE & YES & YES & YES & YES \\
Firm FE & YES & NO & YES & NO \\
Observations & NO & YES & NO & YES \\
Adjusted R-squared & 1,400 & 1,400 & 2,725 & 2,725 \\
\hline
\end{tabular}

Panel B: Over-investing sample regression results

Over-Firm Sample

$$
\text { DistanceFromEfficientInvest }
$$

EfficientTotalInvest

\begin{tabular}{lcccc} 
Post $_{\boldsymbol{t}}$ * LeaseInd $_{\boldsymbol{i}}$ & $\mathbf{2 . 8 6 1} * *$ & $\mathbf{2 . 9 1 6}^{* * *}$ & $\mathbf{3 . 3 5 3}$ & $\mathbf{2 . 4 6 7 *}$ \\
& $(1.198)$ & $(1.094)$ & $(1.812)$ & $(1.447)$ \\
Main Effects & & & & \\
Control Variables & YES & YES & YES & YES \\
Industry FE & YES & YES & YES & YES \\
Firm FE & YES & NO & YES & NO \\
Observations & NO & YES & NO & YES \\
Adjusted R-squared & 1,780 & 1,780 & 630 & 630 \\
\hline
\end{tabular}

Note: This table present the results from estimating equation (1) using ordinary least squares regression. Panel A details our results when we use the sample of under-investing firms to support our estimation. Panel B details our results when we use the sample of over-investing firms to support our estimation. Column 1 and 2 relate to our estimation in the under-investment sample we construct using DistanceFromEfficientInvest, while column 3 and 4 relate to our estimation in the under-investment sample we construct using EfficientTotalInvest. We provide our point estimate for each coefficient and its associated standard errors (in parentheses). We omit our estimates of the coefficients for the control variables and main effects. Columns 1 and 3 relate to our estimates with industry fixed effects where we define industry by the Fama French 48 classification. Columns 2 and 4 relate to our estimates with firm fixed effects. For all specifications, we cluster our standard errors by firm. ***, **, and * denote significance at the 1 percent, 5 percent, and 10 percent level respectively (two-tailed). 
Table 10: Entropy Balancing

\begin{tabular}{|c|c|c|c|}
\hline & LeaseInd $=1$ & LeaseInd $=0$ & Difference \\
\hline CFOSales $_{i t-1}$ & 0.078 & 0.078 & 0.000 \\
\hline$\sigma C F O_{i t-1}$ & 0.057 & 0.057 & 0.000 \\
\hline Dividend $_{i t}$ & 0.652 & 0.652 & 0.000 \\
\hline$R O A_{i t-1}$ & 0.005 & 0.005 & 0.000 \\
\hline Leverage $_{i t-1}$ & 0.340 & 0.340 & 0.000 \\
\hline Zscore $_{i t-1}$ & 1.517 & 1.517 & 0.000 \\
\hline$R \& D_{i t-1}$ & 0.021 & 0.021 & 0.000 \\
\hline Tangibility $_{i t-1}$ & 0.388 & 0.388 & 0.000 \\
\hline$\sigma$ Accruals $_{i t-1}$ & 0.081 & 0.081 & 0.000 \\
\hline lnAssets $_{i t-1}$ & 21.800 & 21.800 & 0.000 \\
\hline AnalystFollow $_{i t}$ & 8.269 & 8.269 & 0.000 \\
\hline InstitutionalOwn $_{i t}$ & 0.058 & 0.058 & 0.000 \\
\hline Inflation $_{i t}$ & 0.017 & 0.017 & 0.000 \\
\hline DefualtSpread $_{i t}$ & 0.943 & 0.943 & 0.000 \\
\hline RiskFree $_{i t}$ & 1.017 & 1.017 & 0.000 \\
\hline SalesGrowth $_{i t-1}$ & 0.092 & 0.092 & 0.000 \\
\hline
\end{tabular}

Panel B: Results of estimation after entropy balancing

(1)

(2)

(3)

(4)

DistanceFromEfficientInvest

EfficientTotalInvest

\begin{tabular}{|c|c|c|c|c|}
\hline Post $_{t} *$ LeaseInd $_{i}$ & $\begin{array}{c}0.890 * \\
(0.463)\end{array}$ & $\begin{array}{c}0.870 * * \\
(0.443)\end{array}$ & $\begin{array}{c}0.455 \\
(0.413)\end{array}$ & $\begin{array}{c}0.443 \\
(0.404)\end{array}$ \\
\hline Main Effects & YES & YES & YES & YES \\
\hline Control Variables & YES & YES & YES & YES \\
\hline Industry FE & YES & NO & YES & $\mathrm{NO}$ \\
\hline Firm FE & NO & YES & NO & YES \\
\hline Observations & 7,200 & 7,200 & 7,200 & 7,200 \\
\hline Adjusted R-squared & 0.128 & 0.268 & 0.167 & 0.267 \\
\hline
\end{tabular}


Panel C: Results of decile estimation after entropy balancing

(1) (2)

DistanceFromEfficientInvest
(3)

EfficientTotalinvest

\begin{tabular}{|c|c|c|c|c|}
\hline Post $_{t} *$ LeaseRank $_{i 10}$ & $\begin{array}{c}\mathbf{2 . 0 6 5} * * * \\
(0.625)\end{array}$ & $\begin{array}{c}\text { 2.213*** } \\
(0.600)\end{array}$ & $\begin{array}{c}\text { 1.671 } * * * \\
(0.537)\end{array}$ & $\begin{array}{c}\mathbf{1 . 3 4 6}^{* * * *} \\
(0.498)\end{array}$ \\
\hline Post $_{t} *$ LeaseRank $_{i 9}$ & $\begin{array}{l}\text { 1.358* } \\
(0.695)\end{array}$ & $\begin{array}{c}1.490 * * \\
(0.665)\end{array}$ & $\begin{array}{c}\mathbf{1 . 0 3 6}^{*} \\
(0.547)\end{array}$ & $\begin{array}{l}\mathbf{1 . 0 2 5} * \\
(0.569)\end{array}$ \\
\hline Post $_{t} *$ LeaseRank $_{i 8}$ & $\begin{array}{l}1.285 * \\
(0.685)\end{array}$ & $\begin{array}{c}1.352 * * \\
(0.671)\end{array}$ & $\begin{array}{c}0.788 \\
(0.557)\end{array}$ & $\begin{array}{c}0.660 \\
(0.554)\end{array}$ \\
\hline Post $_{t} *$ LeaseRank $_{i 7}$ & $\begin{array}{c}0.758 \\
(0.685)\end{array}$ & $\begin{array}{c}0.618 \\
(0.685)\end{array}$ & $\begin{array}{c}0.159 \\
(0.574)\end{array}$ & $\begin{array}{l}0.0963 \\
(0.588)\end{array}$ \\
\hline Post $_{t} *$ LeaseRank $_{i 6}$ & $\begin{array}{c}0.416 \\
(0.692)\end{array}$ & $\begin{array}{c}0.449 \\
(0.678)\end{array}$ & $\begin{array}{l}1.011^{*} \\
(0.579)\end{array}$ & $\begin{array}{c}0.630 \\
(0.593)\end{array}$ \\
\hline Post $_{t} *$ LeaseRank $_{i 5}$ & $\begin{array}{c}0.347 \\
(0.668)\end{array}$ & $\begin{array}{c}0.444 \\
(0.660)\end{array}$ & $\begin{array}{c}0.443 \\
(0.566)\end{array}$ & $\begin{array}{c}0.300 \\
(0.551)\end{array}$ \\
\hline Post $_{t} *$ LeaseRank $_{i 4}$ & $\begin{array}{c}1.004 \\
(0.716)\end{array}$ & $\begin{array}{c}0.921 \\
(0.679)\end{array}$ & $\begin{array}{c}0.652 \\
(0.553)\end{array}$ & $\begin{array}{c}0.663 \\
(0.550)\end{array}$ \\
\hline Post $_{t} *$ LeaseRank $_{i 3}$ & $\begin{array}{c}0.711 \\
(0.576)\end{array}$ & $\begin{array}{c}0.562 \\
(0.561)\end{array}$ & $\begin{array}{c}0.531 \\
(0.492)\end{array}$ & $\begin{array}{c}0.460 \\
(0.460)\end{array}$ \\
\hline Post $_{t} *$ LeaseRank $_{i 2}$ & $\begin{array}{c}0.685 \\
(0.493)\end{array}$ & $\begin{array}{c}0.577 \\
(0.482)\end{array}$ & $\begin{array}{l}0.0527 \\
(0.401)\end{array}$ & $\begin{array}{l}0.0960 \\
(0.383)\end{array}$ \\
\hline Post $_{t} *$ LeaseRank $_{i 1}$ & $\begin{array}{c}0.312 \\
(0.591)\end{array}$ & $\begin{array}{c}0.167 \\
(0.592)\end{array}$ & $\begin{array}{c}0.353 \\
(0.485)\end{array}$ & $\begin{array}{c}0.102 \\
(0.469)\end{array}$ \\
\hline Main Effects & YES & YES & YES & YES \\
\hline Control Variables & YES & YES & YES & YES \\
\hline Industry FE & YES & NO & YES & NO \\
\hline Firm FE & NO & YES & NO & YES \\
\hline Observations & 7,200 & 7,200 & 7,200 & 7,200 \\
\hline Adjusted R-squared & 0.128 & 0.267 & 0.171 & 0.309 \\
\hline
\end{tabular}

Note: Panel A of this table presents a comparison of means between lease firms and non-lease firms after applying entropy balancing to our main sample. Panel B presents our results from estimating equation (1) in the entropy balanced sample.

Panel C presents our results from estimating equation (5) in the entropy balanced sample. For panel B and C, we provide our point estimate for each coefficient and its associated standard errors (in parentheses). We omit our estimates of the coefficients for the control variables included in equation (1) and we omit our estimates of the coefficients for the control variables and main effects included in equation (5). In both panel B and C columns 1 and 2 relate to our estimations using DistanceFromEfficientInvest as the dependent variable, while columns 3 and 4, relate to our estimations using EfficientTotalInvest as the dependent variable. In columns 1 and 3, we include industry fixed effects where we define industry by the Fama French 48 industry specification. In columns 2 and 4, we include firm fixed effects. For all specifications, we cluster our standard errors by firm. $* * *, * *$, and $*$ denote significance at the 1 percent, 5 percent, and 10 percent level respectively (two-tailed). 